\title{
Economic Growth, Volatility, and Cross-Country Spillovers: New Evidence for the G7 Countries
}

\author{
N. Antonakakis ${ }^{* \dagger \ddagger} \quad$ H. Badinger ${ }^{\S}$
}

November 20, 2015

\begin{abstract}
This study examines the linkages between output growth and output volatility in the G7 countries over the period 1958M2-2013M8. Using the VAR-based spillover index approach by Diebold and Yilmaz (2012) we find that: i) output growth and volatility are highly intertwined; ii) spillovers have reached unprecedented levels during the global financial crisis; iii) the US has been the largest transmitter of growth and volatility shocks. Generalized impulse response analyses suggest moderate growth spillovers and sizable volatility spillovers across countries. Cross-variable effects indicate that volatility shocks lead to lower growth, while growth shocks reduce output volatility.
\end{abstract}

Keywords: Output growth, Output growth volatility, Spillover, Vector autoregression, Variance decomposition, Impulse response

JEL codes: C32, E32, F41, F43, F44

\section{Introduction}

The link between economic growth and volatility is theoretically ambiguous. According to Bernanke (1983), output volatility raises economic uncertainty and thus hampers investment due to its irreversible nature, which in turn leads to lower economic growth. Aghion and Howitt (2006) argue that volatility has a negative effect on growth under credit market imperfections that constrain investments during recessions. On the contrary, higher volatility (economic uncertainty) could increase precautionary saving and therefore lead to higher growth rates (Mirman, 1971; Lensink et al., 1999). Optimal portfolio theory suggests that volatile sectors command high investment rates (Imbs, 2007). Finally, a positive effect of volatility on growth could also be due to a Schumpeterian 'cleansing effect' of recessions (Caballero, 1991). ${ }^{1}$

\footnotetext{
${ }^{*}$ Corresponding author: Vienna University of Economics and Business, Department of Economics, Institute for International Economics, Welthandelsplatz 1, 1020, Vienna, Austria, phone: +43 1313364141, fax: +43 131336904141, e-mail: nikolaos.antonakakis@wu.ac.at

${ }^{\dagger}$ University of Portsmouth, Economics and Finance Subject Group, Portsmouth Business School, Portland Street, Portsmouth, PO1 3DE, United Kingdom, phone: ++44 (0)2392844261, fax: ++44 (0)2392844037, email: nikolaos.antonakakis@port.ac.uk

${ }^{\ddagger}$ Webster Vienna Private University, Palais Wenkhaim, Praterstrasse 23, 1020, Vienna, Austria.

$\S$ Vienna University of Economics and Business, Department of Economics, Institute for International Economics, Welthandelsplatz 1, 1020, Vienna, Austria, phone: +43 1313364138, fax: +43 131336904138, e-mail: harald.badinger@wu.ac.at

"Austrian Institute of Economic Research (WIFO), Arsenal, Objekt 20, A-1030, Vienna, Austria, phone: +43 17982601318,e-mail: harald.badinger@wifo.ac.at

${ }^{1}$ See Imbs (2007) for an extended discussion of the link between volatility and growth.
} 
The empirical literature on the relation between output volatility and economic growth, which has used cross-section and panel data models as well as time series analyses of individual countries, adds to this controversy. Ramey and Ramey (1995), Lensink et al. (1999), Martin and Ann Rogers (2000), Fatás (2002), Rafferty (2005), Badinger (2010) and Posch and Wälde (2011) find that output growth tends to be lower during periods of higher volatility. On the other hand, Kormendi and Meguire (1985), Grier and Tullock (1989), Caporale and McKiernan (1996), Fountas and Karanasos (2006) and Lee (2010) find that countries with higher output volatility tend to experience higher economic growth rates. ${ }^{2}$

Identifying the relationship between economic growth and volatility is aggravated by their complex and intricate linkages. First, causality may run not only from volatility to growth but also from growth to volatility, a point already made by Stiglitz (1993). The empirical literature on this linkage is rather sparse. Fountas and Karanasos (2006) find that higher output growth leads to significantly lower output volatility in two out of the G3 countries (Germany and the US) between the mid-19th century and 1999, while Lee (2010), who uses a panel-GARCH approach for the G7 countries over the 1965-2007 period, finds no significant relationship. More recently, Kodama (2014) finds evidence of a negative casual effect of growth on volatility for a sample of developing countries over the 1966-2005 period.

Second, in a world of highly interdependent economies, economic growth and output volatility spillovers from foreign countries are relevant determinants of a country's own economic growth and output volatility. Due to their high degree of economic integration, this holds particularly true for developed countries, for which a strong role of growth spillovers (Antonakakis and Scharler, 2012) and volatility spillovers (Antonakakis and Badinger, 2012a) has been found.

The aim of this paper is to shed more light on this controversy by examining the linkages between output volatility and economic growth both within and across the G7 countries. As a first study on the linkages between growth and volatility, we use the VAR-based spillover index approach recently introduced by Diebold and Yilmaz (2009, 2012), which is particularly suited for the investigation of systems of highly interdependent variables. ${ }^{3}$ Especially, the variant of Diebold and Yilmaz (2012) which uses a generalized vector autoregressive framework, in which forecast-error variance decompositions are invariant to the ordering of the variables (in contrast to Cholesky-factor identification used in (Diebold and Yilmaz, 2009)). In the context of the present study, this is particularly important since it is hard if not impossible to justify one particular ordering of the variables on output growth and volatility among the countries. Thus by fully accounting for the pattern of observed correlation between shocks it increases the relevance from a policy perspective in light of the increased synchronization of shocks and the growing importance of a 'world component' in countries' business cycles (Kose et al., 2003).

A very closely related study to ours, is the one of Yilmaz (2009) that examines output growth spillovers in the G7 countries. Unlike Yilmaz (2009), however, in this study we examine output growth volatility in addition to output growth spillovers. In particular, our study enables an encompassing analysis to unravel the two-way relationships between output growth and volatility, both within countries and accounting for spillovers between countries. Moreover, it allows an assessment of the evolution of spillovers between output volatility and economic growth over time, the identification of the main receivers and transmitters of shocks, and the quantification of their magnitude using impulse response analyses. These are the major contributions of this

\footnotetext{
${ }^{2}$ For a comprehensive review and discussion of empirical studies, see Döpke (2004) and Norrbin and Yigit (2005).

${ }^{3}$ This VAR-based spillover index methodology has already attracted significant attention by the economic literature, investigating issues such as stock market interdependencies, volatility spillovers, business cycle spillovers and bond yields spillovers (see, inter alia, McMillan and Speight, 2010; Yilmaz, 2010; Bubák et al., 2011; Antonakakis, 2012b; Zhou et al., 2012; Antonakakis and Vergos, 2013; Antonakakis and Badinger, 2014; Narayan et al., 2014).
} 
study.

Based on monthly observations of seasonally adjusted industrial production growth as a proxy measure for output growth for each of the G7 countries over the period 1985M11-2013M8 we identify several empirical regularities: i) output growth and volatility are highly intertwined, with spillovers taking place into all four directions; ii) the importance of spillovers has increased and reached unprecedented levels during the recent financial and economic crisis; iii) the US has been the largest transmitter of output growth and volatility shocks to other countries. Generalized impulse response analyses point to moderate growth spillovers and sizable volatility spillovers across countries, suggesting that volatility shocks quintuplicate in the long-run. The cross-variable effects turn out negative: volatility shocks lead to lower economic growth, while growth shocks tend to reduce output volatility. Our findings underline the increased vulnerability of the G7 countries to destabilizing shocks and their detrimental effects on economic growth, which are sizeably amplified through international spillover effects and the associated repercussions. In addition, our results suggest that the implementation of stabilization policies to mitigate short-run economic fluctuations contribute to long-run economic growth, while growth-enhancing policies promote economic stability.

The remainder of the paper is organized as follows. Section 2 discusses the application of the spillover index approach to disentangle the intricate relationships between volatility and growth and describes the data used. Section 3 presents the empirical findings. Section 4 summarizes the results and concludes.

\section{Empirical Model, Methodology, and Data}

\subsection{Definition of Spillover Indices for Output Growth and Volatility}

In the following, we outline our application of the spillover index approach introduced by Diebold and Yilmaz (2009). Building on the seminal work on VAR models by Sims (1980) and the wellknown notion of variance decompositions, it allows an assessment of the contributions of shocks to variables to the forecast error variances of both the respective and the other variables of the model. Using rolling-window estimation, the evolution of spillover effects can be traced over time and illustrated by spillover plots.

For the purpose of the present study, we use the variant of the spillover index in Diebold and Yilmaz (2012), which extends and generalizes the method in Diebold and Yilmaz (2009) in two respects. First, they introduce refined measures of directional spillovers and net spillovers, providing an 'input-output' decomposition of total spillovers into those coming from (or to) a particular source (variable) and allowing to identify the main recipients and transmitters of spillovers.

Second, in line with Koop et al. (1996) and Pesaran and Shin (1998), Diebold and Yilmaz (2012) use a generalized vector autoregressive framework, in which forecast-error variance decompositions are invariant to the ordering of the variables (in contrast to Cholesky-factor identification used in (Diebold and Yilmaz, 2009)). In the context of the present study, this is particularly important since it is hard if not impossible to justify one particular ordering of the variables on output growth and volatility among the countries. Of course, the generalized VAR framework has advantages and drawbacks. A disadvantage is that it aggravates the identification of causal effects in a strict sense in the impulse response analysis. On the other hand, by fully accounting for the pattern of observed correlation between shocks it increases the relevance from a policy perspective in light of the increased synchronization of shocks and the growing importance of a 'world component' in countries' business cycles (Kose et al., 2003). We will nevertheless explore the robustness of the results against a more structural approach, using 
Cholesky-factorizations with alternative orderings.

Starting point for the analysis is the following $P$-th order, $K$-variable VAR

$$
y_{t}=\sum_{i=1}^{P} \Theta_{i} y_{t-i}+\varepsilon_{t}
$$

where $y_{t}=\left(y_{1 t}, y_{2 t}, \ldots, y_{K t}\right)$ is a vector of $K$ endogenous variables, $\Theta_{i}, i=1, \ldots, P$, are $K \times K$ parameter matrices and $\varepsilon_{t} \sim(0, \Sigma)$ is a vector of disturbances that are independently distributed over time; $t=1, \ldots, T$ is the time index and $k=1, \ldots, K$ is the variable index. For each of the G7 countries considered ( $C A N, F R A, G E R, I T A, J P N, U K, U S)$, the VAR given by Equation (1) contains observations on output growth $\left(g_{n, t}\right)$, and output growth volatility $\left(\sigma_{n, t}, n=1, \ldots, 7\right)$, with $n$ denoting the country index. Hence, with 7 countries and 2 variables, our VAR is made up of $K=14$ variables, i.e., $y_{t}=\left[g_{t}^{\prime} \sigma_{t}^{\prime}\right]^{\prime}$, where $g_{t}$ and $\sigma_{t}$ are $7 \times 1$ vectors with observation on output growth and output volatility for each of the 7 countries respectively. For notational simplicity, both variables $g_{n, t}$ and $\sigma_{n, t}$ in (1), are referred to as $y_{i, t}$ and indexed by $i=1, \ldots$, $K=14$ in the following.

The two key variables, output growth and output growth volatility are derived from monthly, seasonally adjusted data on industrial production for the G7 countries over the period from January 1958 to August 2013, taken from the IMF's International Financial Statistics. Monthly growth rates of real industrial production are obtained using the first difference of their logarithms. ${ }^{4}$ The use of the growth rate of industrial production as a proxy of economic growth (business cycles) has been a common practice in many studies (see, Bjørnland and Leitemo, 2009; Laopodis, 2009; Imbs, 2010; Espinoza et al., 2012; Peersman and Van Robays, 2012, among others). Given the lack of data at a higher than monthly frequency, precluding the use of within-period realized volatility measures, we use the 12-month rolling windows standard deviation of industrial production growth as measure of (output growth) volatility. ${ }^{5}$ Results from the Augmented Dickey-Fuller (ADF) tests, which are reported in Table 1 below, reject the null hypothesis of a unit root for each of our (country-specific) series $g_{n}$ and $\sigma_{n}$, justifying the use of a VAR model for the subsequent analysis.

An alternative approach would be to use conditional measures of volatility derived from GARCH models (see, for instance, Fountas and Karanasos, 2006; Fountas et al., 2004; Caporale and McKiernan, 1998). Our choice of an unconditional volatility measure is motivated by our use of a VAR model, including both growth and volatility as dependent variables, which imposes a structure on the conditional variances of the dependent variables that is entirely separate from (and presumably inconsistent) with the conditional variance structure that would be implied by the use of a GARCH model to estimate the volatilities. ${ }^{6}$

Key to the dynamics of the system is the moving average representation of model (1), which is given by $y_{t}=\sum_{j=0}^{\infty} A_{j} \varepsilon_{t-j}$, where the $K \times K$ coefficient matrices $A_{j}$ are recursively defined as $A_{j}=\Theta_{1} A_{j-1}+\Theta_{2} A_{j-2}+\ldots+\Theta_{p} A_{j-p}$, where $A_{0}$ is the $K \times K$ identity matrix and $A_{j}=0$ for $j<0$.

Following Diebold and Yilmaz (2012) we use the generalized VAR framework of Koop et al. (1996) and Pesaran and Shin (1998), which produces variance decompositions invariant to the

\footnotetext{
${ }^{4}$ Thus the reference point of this paper is to examine the short- to medium- term dynamics of the relationship between output volatility and economic growth.

${ }^{5}$ The use of rolling windows of standard deviation of output growth has been used in previous studies as a measure of output volatility (see, for instance, Blanchard and Simon, 2001; Kose et al., 2005).

${ }^{6}$ Despite that, we have examined the outcome of the results with the use of conditional measure of volatility obtained from GARCH models, instead of an unconditional measure, and our results remained qualitatively very similar to those presented below (see, working paper version of the paper by Antonakakis and Badinger, 2012b). In fact, the correlation between the unconditional and the conditional volatility measure is 0.80 .
} 
variable ordering. According to this framework, the $H$-step-ahead forecast error variance decomposition is

$$
\phi_{i j}(H)=\frac{\sigma_{j j}^{-1} \sum_{h=0}^{H-1}\left(e_{i}^{\prime} A_{h} \Sigma e_{j}\right)^{2}}{\sum_{h=0}^{H-1}\left(e_{i}^{\prime} A_{h} \Sigma A_{h}^{\prime} e_{i}\right)},
$$

where $\Sigma$ is the (estimated) variance matrix of the error vector $\varepsilon, \sigma_{j j}$ the (estimated) standard deviation of the error term for the $j$-th equation and $e_{i}$ a selection vector with one as the $i$-th element and zeros otherwise. This yields a $K \times K$ matrix $\phi(H)=\left[\phi_{i j}(H)\right]_{i, j=1, \ldots 14}$, where each entry gives the contribution of variable $j$ to the forecast error variance of variable $i$. The main diagonal elements contains the (own) contributions of shocks to the variable $i$ to its own forecast error variance, the off-diagonal elements show the (cross) contributions of the other variables $j$ to the forecast error variance of variable $i$.

Since the own and cross-variable variance contribution shares do not sum to one under the generalized decomposition, i.e., $\sum_{j=1}^{K} \phi_{i j}(H) \neq 1$, each entry of the variance decomposition matrix is normalized by its row sum, such that

$$
\tilde{\phi}_{i j}(H)=\frac{\phi_{i j}(H)}{\sum_{j=1}^{K} \phi_{i j}(H)}
$$

with $\sum_{j=1}^{K} \tilde{\phi}_{i j}(H)=1$ and $\sum_{i, j=1}^{K} \tilde{\phi}_{i j}(H)=K$ by construction.

This ultimately allows to define a total (volatility) spillover index, which is given by

$$
S(H)=\frac{\sum_{i, j=1, i \neq j}^{K} \tilde{\phi}_{i j}(H)}{\sum_{i, j=1}^{K} \tilde{\phi}_{i j}(H)} \times 100=\frac{\sum_{i, j=1, i \neq j}^{K} \tilde{\phi}_{i j}(H)}{K} \times 100
$$

which gives the average contribution of spillovers from shocks to all (other) variables to the total forecast error variance.

This approach is quite flexible and allows to obtain a more differentiated picture by considering directional spillovers: Specifically, the directional spillovers received by variable $i$ from all other variables $j$ are defined as

$$
S_{i \leftarrow j}(H)=\frac{\sum_{j=1, j \neq i}^{K} \tilde{\phi}_{i j}(H)}{\sum_{i, j=1}^{K} \tilde{\phi}_{i j}(H)} \times 100=\frac{\sum_{j=1, j \neq i}^{K} \tilde{\phi}_{i j}(H)}{K} \times 100
$$

and the directional spillovers transmitted by variable $i$ to all other variables $j$ as

$$
S_{i \rightarrow j}(H)=\frac{\sum_{j=1, j \neq i}^{K} \tilde{\phi}_{j i}(H)}{\sum_{i, j=1}^{K} \tilde{\phi}_{j i}(H)} \times 100=\frac{\sum_{j=1, j \neq i}^{K} \tilde{\phi}_{j i}(H)}{K} \times 100 .
$$

Notice that the set of directional spillovers provides a decomposition of total spillovers into those coming from (or to) a particular source. In the present application this means that our spillover matrix $\phi(H)$ is made up of four blocks: the two main diagonal blocks $(i, j=1, \ldots, 7$; and $i, j=8, . ., 14)$ reflecting growth-to-growth and volatility-to-volatility spillovers respectively; and the off-diagonal blocks $(i=1, \ldots, 7, j=8, \ldots 14$; and $i=8, \ldots, 14, j=1, \ldots 7)$, reflecting growth-to-volatility and volatility-to-growth spillovers.

The spillover index approach provides measures of the intensity of interdependence across countries and variables and allows a decomposition of spillover effects by source and recipient. The magnitude of the spillovers will then be quantified using impulse response analyses. 


\subsection{Descriptive statistics}

Before turning to the estimation results, Table 1 provides summary statistics of our monthly output growth and volatility series. Results are reported for both sample periods, i.e., 1985M112006M4 (246 observations) and 1985M11-2013M8 (334 observations), which will be used in the econometric analysis below. The choice of these two sample periods is based on the results obtained from the structural break test by Qu and Perron (2007) described below. For the sample with the crisis included, the monthly average output growth was highest in Canada with $0.19 \%$ (followed by the US and Germany) and lowest in the UK with $0.025 \%$. The largest volatilities are observed for Japan and Germany, whereas Canada and US showed the most stable growth of industrial production.

\section{[Insert Table 1 here]}

A look at the unconditional (contemporaneous) correlations in Table 1 reveals several interesting features of our data. First, as expected, the correlations among growth rates and volatilities are positive in the vast majority of cases, both within and between countries. Second, with very few exceptions, the correlations between volatility and growth are negative. Overall, these correlations are more pronounced when the crisis period as of mid-2007 is included.

\section{Empirical findings}

In the following we report the results from our empirical analysis, starting with the estimates of the spillover index and its subindices, defined in Equations (4)-(6). We then consider the evolution of spillovers indices over time and finally turn to the results from the impulse response function analyses.

Applying the Qu and Perron (2007) test on the full sample (1958M2-2013M8), three significant breaks were found, namely, in 1968M10, 1985M10, and 2006M5.

[Insert Table 2 here]

Thus, in the following, we restrict our analysis to the post 1985 period (after the Great Moderation) with and without the latest recession. According to the Qu and Perron (2007) test, we will consider two samples: 1985M11-2006M4, and 1985M11-2013M8. For both sample periods, a lag-length of 1 was chosen in the estimation of the VAR-model (1), based on the Schwarz Bayesian information (BIC) criterion. ${ }^{7}$

\subsection{Spillover Indices}

Tables 3 and 4 report the estimates of the spillover indices for the two sample periods (with and without the crisis) based on 12-months ahead forecast error variance decompositions. Before discussing the results, let us describe the elements of these two tables. In Panel A of Tables 3 and 4 , the $i j$-th entry is the estimated contribution to the forecast error variance of variable $i$ coming from innovations to variable $j$ (see Equation (2)). Note that each variable (index) is associated with one of the G7 countries' output growth or volatility. Hence, the diagonal elements $(i=j)$ measure own-variable spillovers of output growth and volatility within countries, while the off-diagonal elements $(i \neq j)$ capture cross-variable spillovers between output growth and

\footnotetext{
${ }^{7}$ The Akaike Information Criterion (AIC) also suggested the same number of lags. We have also explored the robustness of our results displayed below by increasing the number of lags up to 4 and our results remained qualitatively similar. These results are available upon request.
} 
volatility within and between countries. In addition, the row sums excluding the main diagonal elements (labeled 'Contributions from others', see Equation (5)) and the column sums (labeled 'Contributions to others', see Equation (6)) report the total volatility spillovers 'to' (received by) and 'from' (transmitted by) each variable. The total volatility spillover index defined in Equation (4), given in the lower right corner of panel $\mathrm{A}$ in Tables Tables 3 and 4, is approximately ${ }^{8}$ equal to the grand off-diagonal column sum (or row sum) relative to the grand column sum including diagonals (or row sum including diagonals), expressed in percentage points.

\section{[Insert Table 3 here] \\ [Insert Table 4 here]}

Summarizing the rich information in Tables 3 and 4, we identify several empirical regularities. In general, growth-to-growth spillovers and volatility-to-volatility spillovers are larger within countries than between countries. For instance, in the sample without (with) the latest recession, innovations in US output growth are responsible for $73.3 \%(61.6 \%)$ of the 12 -month ahead forecast error variance of output growth in the US, but only for $7.5 \%(8.5 \%)$ of Canada. The same holds true for spillovers from volatility-to-volatility. For instance, innovations to volatility in France explain $85.0 \%(81.7 \%)$ of the 12 -month ahead forecast error variance of volatility in France, but only $0.1 \%$ (0.1\%) for Canada.

Comparing the results for the two time periods, we generally observe an increased importance of spillovers effects during the recent crisis. The total spillover index, which is reported in the lower right part of panel $\mathrm{A}$ and essentially distills all spillovers effects between and within countries into a single measure, has increased from $23.0 \%$ to $32.1 \%$ as a result of the recent financial and economic crisis.

The finding of an increased importance of spillover effects is particularly pronounced for volatility spillovers originating in the US: The average contribution of US volatility spillovers to other countries volatility amounted to $2.5 \%$ before the crisis and increased to an average share of $5.4 \%$ including the crisis (ranging from $0.1 \%$ to $9.3 \%$ ). This result is further supported by the gross spillover indices by country reported in Panels A of Tables 3 and 4 . Overall, the contribution to and from others has increased. Moreover, the US holds the dominant position as a transmitter of volatility spillovers, while Japan and the US hold the dominant position as a transmitter of output growth spillovers (see Equation (6)). The latter finding is in line with Yilmaz (2009), who finds that the US and Japan are the major transmitters of output growth shocks to other industrialized (G6) countries. This finding is also supported by the results of the main variance decomposition approach reported in Table A.1 in the Appendix; for instance, a $9.3 \%$ portion of volatility in Japan is explained by US volatility.

Our results are in line with Eickmeier et al. (2011). Focusing on the role of financial shocks originating in the US during the recent financial and economic crisis, they find that the 'global financial crisis shock' was very large by historical standards and that US shocks explain one third of the variation in GDP growth on average over all countries in 2008-2009, compared with a little less than 10\% over the 1971-2007 period. While the results are not directly comparable since they focus on financial rather than real shocks and use an alternative method (time-varying factoraugmented VARs), the large vulnerability of countries due to the increased interconnectedness of the world economy is a common finding.

In order to provide a more differentiated picture, Panels B in Tables 3 and 4 further parse the directional spillovers into growth-to-growth spillovers and volatility-to-growth spillovers ('Contribution to others' $g$ '), as well as growth-to-volatility spillovers and volatility-to-volatility spillovers

\footnotetext{
${ }^{8}$ The approximate nature is due to the fact that the contributions of the variables in the variance decompositions do not sum to one and have to be normalized (see Equation (3)).
} 
('Contribution to others' $\sigma^{\prime}$ ). We can see that in the pre-crisis sample, $45.36 \%$ of all four gross directional spillovers are from growth-to-growth, with France and Italy being the biggest contributors of output growth spillovers to the remaining G7 countries. The shares of volatilityto-growth and growth-to-volatility spillovers are smaller with an average of $11.86 \%$ and $8.62 \%$, respectively. Finally, with a share of one third, volatility-to-volatility spillovers make up a substantial fraction of total spillovers.

We have checked the robustness of the results using a Cholesky instead of the generalized decomposition approach, assuming that volatility comes first and ordering the countries by size. Detailed results for the period including the crisis are reported in Table A.2 in the Appendix. Overall, the results turn out qualitatively identical (the total spillover index increases by onethird, when the crisis period is included) but spillovers turn out smaller in magnitude: For the full period, the total spillover index amounts to $20.5 \%$ and again the US turns out to be the main contributor to growth and volatility spillovers. For the period up to 2006M6 the total spillover index amounts to $14.7 \%$. These results are insensitive against assuming that growth comes first in the ordering of the variables; the corresponding spillover indices amount to $20.1 \%$ and $14.3 \%$ respectively. ${ }^{9}$

\section{$3.2 \quad$ Spillover Plots}

While we have split our sample according to the results of the structural break tests, the use of an average measure of growth and volatility spillovers over a fairly long period might mask potentially interesting information on secular or cyclical movements in spillover effects. Hence, we estimate the model in Equation (1) using 180-month rolling windows and calculate the variance decompositions and spillover indices for each subsample. As a result, we obtain time series of estimated spillover indices, allowing us to judge the evolution of total and directional growth and volatility spillover within and between countries over time.

[Insert Figure 1 here]

Figure 1 presents the results for the time-varying total spillovers index obtained from the 180months rolling windows estimation for the sample 1985M11-2013M8. As can be seen, before the crisis output growth and volatility spillovers in the G7 countries remained relatively stable and around $27 \%$ and then surged to unprecedented levels above $45 \%$ following the recent global financial and economic crisis. The sharp increase in the output growth and output growth volatility spillover index in the late 2008 to early 2009, depicted in Figure 1, is in line with the output growth spillover index results reported in Yilmaz (2009). Overall these results are in line with the average estimates for the subperiods, suggesting an increased in the role of spillovers during the recent crisis period.

The results for the total volatility spillover index are suggestive but they might discards directional information that is contained in the "Contribution to others" row (Equation (5)) and the "Contribution from others" column (Equation (6)) in Panel A of Tables 3 and 4. Figure 2 presents the estimated 180-month rolling windows directional spillovers from each of the variables to others (corresponding to the "Contribution to others" row in Panel A of Table 4 for the samples including the crisis. According to this figure, the contribution of directional volatility spillovers increases to a share of $10 \%$. Japan, followed by the US, are the dominant transmitters of output growth shocks. In terms of output volatility spillovers, the largest shares are observed in Japan, Italy and US, however, the increase of volatility spillovers in Ialy and

\footnotetext{
${ }^{9}$ Finally, accounting for common shocks to the countries such as changes in the oil price did not affect our empirical findings, such that we stick with the VAR model as given by equation (1).
} 
Japan is relatively short-lived, while volatility spillovers from US are on an increasing trend since the crisis erupted. In other words, there is increased influence of directional spillovers, with the US lying at the epicenter of spillovers during the recent economic crisis through its dominant role as transmitter of volatility and growth shocks to the other G7 countries.

[Insert Figure 2 here]

\subsection{Impulse Responses}

Having established the strong role and growing importance of spillover effects we next turn to an impulse response analysis in order to shed more light on the intricate relationships between volatility and growth. As already outlined above the results should be interpreted with care. In particular, the effects of shocks to single variables should not be interpreted as causal (in the sense of 'all else being equal'), given that the generalized impulse responses account for the observed correlation of shocks across countries. This is a limitation on the one side. However, given the increased synchronization of shocks and business cycles across countries (see, for instance, Antonakakis, 2012a), we do not expect shocks to countries to appear in isolation from each other; and since there is no strong reason to assume that the correlation pattern of shocks to countries will change fundamentally in the short- to the medium-run, we argue that the generalized impulse responses can be regarded as indicative for the effects of future shocks.

Results of the generalized impulse response analysis are reported for the period 1985M112013M8 (including the crisis), using one standard deviation shocks to each of the G7 countries' output growth and volatility (see Pesaran and Shin, 1998). We first report the results for shocks to the US in light of its dominant role as transmitter of spillover effects ${ }^{10}$ and then provide a broader picture in terms of cross-country averages of impulse response effects of shocks to single countries.

Generalized impulse responses (GIR) of shocks to the US and $95 \%$ confidence bands are illustrated in Figure 3. Panel a) of Figure 3 shows that output growth shocks to the US have positive, but relatively short-lived effects on growth, compared with the relatively more persistent effects of volatility shocks in panel b) of Figure 3. Specifically, the effects of output growth shocks to the US on own- and cross- countries' output growth dissipate after some 12 months, whereas the effects of shocks to volatility on own and cross- countries' volatility fade away after some 5 years.

\section{[Insert Figure 3 here]}

Turning to the cross-variable (i.e., growth-to-volatility and volatility-to-growth) spillovers, panel c) of Figure 3 shows that overall, volatility shocks to the US have negative effects on growth, which fade away after some 2 years, while the negative effects of growth shocks to the US on own- and cross- countries' volatility fade away after some 5 years as shown in panel d) of Figure 3. From the viewpoint of policy implications, these results are very important, as they suggest that the implementation of stabilization policies to mitigate short-run economic fluctuations may contribute to economic growth, and that growth-enhancing policies may also affect economic stability.

In order to provide a summary picture of the bottom line effect of growth and volatility shocks we next calculate for each country the cumulative effects of a one-standard deviations

\footnotetext{
${ }^{10}$ Impulse responses for shocks to other countries and for the pre-crisis sample are qualitatively similar and not presented, however, are available from the authors upon request.
} 
shock to growth (volatility) on the respective country's growth (volatility), referred to as 'withincountry' response in the following. ${ }^{11}$ Table 5 reports the averages of the cumulative effects i) of growth shocks on growth and on volatility (first column), and ii) of volatility shocks on growth and on volatility (second column) for the sample period up to 2013M8. ${ }^{12}$ The cumulative effects are reported for time horizons of 6, 12, 24, 36. 48 and 60 months. Since the effects of shocks have fully materialized after 5 years (compare Figure 3), the cumulative 60-months responses can be interpreted as overall bottom line effect of incipient shocks including spillover effects and the associated repercussions.

Regarding the direction of the effects, notice first that - as expected - volatility and growth shocks have positive and multiplied effects on 'themselves'. Of particular interest are the impulse response effects across variables, i.e., the response of a country's growth rate (volatility) to shocks to volatility (growth) of the respective country. As evident from Table 5 we find a negative effect of volatility shocks on economic growth, and also a negative effect of output growth shocks on volatility. It is worth emphasizing that the long-term cumulative impulse responses reflect level rather than permanent growth rate effects.

The magnitude of the cumulative response effects has to be judged against the size of the incipient shock, which corresponds to the standard deviation of the error term in the respective equation of the VAR. In order to facilitate the interpretation and to make our results comparable with other studies, Table 5 reports (country-specific averages of) the implied response multipliers, defined as the cumulative impulse response effect divided by the size of the incipient shock. In the discussion of the results we focus on the multiplier effects in the following. We start with a discussion of growth-to-growth and volatility-to-volatility spillovers and then turn to the cross-variable effects, i.e., the spillovers from growth-to-volatility and vice versa.

Notice first that the long-run multiplier effects of growth shocks are fairly small with a value close to unity (see the third column of Table 5). This result masks a bit that there are substantial spillover effects to other countries. The 'cross-country' multiplier of shocks to other countries (not reported in Table 5), which is defined as average multiplier of the six G7 countries' growth in response to growth shocks to the other country amounts to 0.41 . What the rather small 'within-country' multiplier thus suggests is that that growth spillovers appear to mainly materialize in 'one wave' and that the repercussions and feedback effects to the country of origin are moderate.

\section{[Insert Table 5 here]}

In contrast, the long-run multiplier effects of volatility shocks are sizeable with an average 'within-country' response multiplier of 5.9. In line with previous studies this highlights the role of international volatility spillovers as a crucial determinant of countries' output volatility. Carare and Mody (2012), who use factor-structural vector autoregressive models for a sample of 22 countries over the period 1960-2007, find that 50-75\% of total volatility in the post-1995 period is due to international spillovers. Our multiplier of 5.9 in response to volatility shocks suggests that some $15 \%$ of the total increase in volatility is due to the incipient shock and that the remaining $85 \%$ are triggered by international spillover effects. Since our sample also includes the recent crisis, during which spillover effects have surged according to our estimates and those of Eickmeier et al. (2011), we would expect somewhat larger effects of volatility shocks. (For

\footnotetext{
${ }^{11}$ Notice that with a stationary VAR the cumulative growth rate effects of one-time shocks have to be interpreted as level effects and should not be confused with permanent effects on the growth rate. The multiplier for volatility shocks can be regarded as the sum of the uncertainty introduced over time by a single shock materializing in period $t$.

${ }^{12}$ The corresponding effects for the pre-crisis sample, which are reported in Table A.3 in the Appendix are qualitively identical though quantitatively smaller in magnitude.
} 
the pre-crisis period, the multiplier turns out smaller with some 4.24, see Table A.3). Volatility shocks and uncertainty appear to be highly contagious, persistent, and self-enforcing through large feedback effects.

Turning to the cross-variable effects, we find a multiplier of -0.33 for the effect of growth on volatility. As one of the rare studies on this link, Fountas and Karanasos (2006) obtain smaller coefficients of -0.034 for Germany and -0.018 for the USA, using univariate time series analyses. The larger magnitude of our estimates that are based on more countries and account for crosscountry spillovers is plausible and also appears to be largely driven by the crisis period. ${ }^{13}$ For the sample up to $2006 \mathrm{M} 4$, the growth-volatility multiplier is much smaller with a value of -0.036 (see Table A.3) and in line with Fountas and Karanasos (2006).

Regarding the effects of shocks to volatility on economic growth, the multiplier effect amounts to -1.67 (and -1.56 for the pre-crisis sample). Hence, output volatility exerts a negative and sizeable effect on economic activity. Comparing our results to previous studies that have estimated the effect of volatilty of growth using large cross-sections of countries, our effects turn out larger in magnitude. Ramey and Ramey (1995) obtain coefficients for the effect of volatility on economic growth in a range of -0.4 to -0.5. The estimates by Fatás and Mihov (2003) are closer to ours with a coefficient of -0.8. Given the uncertainty involved in our point estimates, this discrepancy should not be overemphasized. However, the larger magnitude implied by our estimates could be due to the fact that the cross-sectional estimates of the aforementioned studies (relating country-specific growth to country-specific volatility) do not fully capture the reinforcing effects of international growth and volatility spillovers that are captured through the dynamics of our system.

Again we explored the robustness of the results using a Cholesky decomposition, assuming that volatility (growth) comes first and ordering the countries by size. Results are given in detail in Table A.4 in the Appendix. Qualitatively, these results turn out very similar. In particular, for the sample period 1985M11-2013M8, the volatility-volatility multiplier amounts to 4.32 (compared with 5.94 under the generalized impulse response analysis), the growthgrowth multiplier to 1.71 (compared with 1.04 under the generalized impulse response analysis). Regarding the cross-spillovers, we again find that volatility shocks reduce economic growth with a multiplier of -1.76 , while positive growth shocks are associated with lower volatility (with a multiplier of -0.08). The magnitude of these effects is reduced if the crisis is excluded (as it is the case under the generalized impulse response analysis).

As a final robustness check, we split up our VAR into two subsystems, containing only growth and only volatility respectively. The results for the spillover indices and the growth-togrowth and volatility-to-volatility multipliers are reported in Tables A.5 to A.8 of the Appendix. Reassuringly the results hold up for these subsets of variables and turn out qualitatively identical and quantitatively very similar, both with respect to the spillover indices (and the change when the crisis is included), as well as far as the impulse response multipliers are concerned.

\section{Conclusions}

This study considers the linkages between output growth and output volatility for the sample of the G7 countries over the period 1958M2-2013M8, thereby paying particular attention to spillovers within and between countries. Using spillover index estimates in the spirit of Diebold and Yilmaz (2012), we identify several empirical regularities: i) In line with theoretical arguments, volatility and growth turn out empirically highly intertwined, with spillovers taking

\footnotetext{
${ }^{13}$ Kodama (2014), who examines the effects of growth on volatility in developing countries obtains a coefficient between -0.40 and -0.76 .
} 
place into all four directions, i.e., both from growth to growth (volatility to volatility) between countries as well as from volatility to growth within and between countries (and vice versa). ii) The importance of spillovers has increased and reached unprecedented levels during the recent financial and economic crisis. iii) Among the G7 countries, the US turns out as the largest transmitter of output and volatility shocks to other countries.

Generalized impulse response analyses point to positive though moderate growth-to-growth spillovers and sizeable volatility-to-volatility spillovers, suggesting that volatility shocks quintuplicate in the long run through international contagion effects and the associated repercussions. Regarding the cross-variable effects, volatility shocks turn out to have a negative effect on economic output. We also find evicence for a negative effect of growth on volatility in line with the theoretical arguments that higher growth triggers higher inflation which is in turn associated with lower output volatility (Taylor effect). These results suggest that stabilization policies to mitigate short-run economic fluctuations contribute to economic growth, while growth-enhancing policies promote economic stability. Finally, qualitatively, our results are in line with previous studies that have considered one-way linkages between volatility and growth within countries. However, the magnitude of the estimated effects turns out larger, since our encompassing approach appears to more completely capture the reinforcing propagation effects and dynamics of growth and volatility spillovers, both within and between countries.

Our findings underline the increased vulnerability of the G7 countries to local and joint destabilizing shocks and their detrimental effects on economic growth, which are sizeably amplified due to the high degree of economic integration. On the positive side, they highlight the potentially huge gains (in terms of stabilization and growth multipliers) from international policy coordination in the implementation of macroprudential stabilization policies, which may result in a virtuous cycle of higher growth and lower volatility.

Overall, our results on the link between economic growth and volatility shed more light on the ambiguous results reported in previous studies, suggesting a robust negative relationship of volatility to growth and vice-versa, and a robust positive growth and volatility relationship.

\section{Acknowledgements}

The authors wish to thank the editors (Sushanta Mallick and Paresh Narayan) and one anonymous referee for very helpful suggestions on a previous version of this paper. The usual disclaimer applies.

\section{References}

Aghion, P., Howitt, P., 2006. Joseph Schumpeter Lecture Appropriate Growth Policy: A Unifying Framework. Journal of the European Economic Association 4 (2-3), 269-314.

Andrews, D. W. K., 1991. Heteroscedasticity and Autocorrelation Consistent Covariance Matrix Estimation. Econometrica 59 (3), 817-858.

Antonakakis, N., 2012a. Business Cycle Synchronization During US Recessions Since the Beginning of the 1870s. Economics Letters 117 (2), 467-472.

Antonakakis, N., 2012b. Exchange Return Co-movements and Volatility Spillovers Before and After the Introduction of Euro. Journal of International Financial Markets, Institutions and Money 22 (5), 1091-1109. 
Antonakakis, N., Badinger, H., 2012a. International Spillovers of Output Growth and Output Growth Volatility: Evidence from the G7. International Economic Journal 26 (4), 635-653.

Antonakakis, N., Badinger, H., 2012b. Output Volatility, Economic Growth, and Cross-Country Spillovers: New Evidence for the G7 Countries. Department of Economics Working Papers wuwp141, Vienna University of Economics, Department of Economics.

Antonakakis, N., Badinger, H., 2014. International Business Cycle Spillovers since the 1870s. Applied Economics 46 (30), 3682-3694.

Antonakakis, N., Scharler, J., 2012. The Synchronization of GDP Growth in the G7 During US Recessions. Applied Economics Letters 19 (1), 7-11.

Antonakakis, N., Vergos, K., 2013. Sovereign Bond Yield Spillovers in the Euro Zone During the Financial and Debt Crisis. Journal of International Financial Markets, Institutions and Money 26, 258-272.

Badinger, H., 2010. Output Volatility and Economic Growth. Economics Letters 106 (1), 15-18.

Bernanke, B. S., 1983. Irreversibility, Uncertainty, and Cyclical Investment. The Quarterly Journal of Economics 98 (1), 85-106.

Bjørnland, H. C., Leitemo, K., 2009. Identifying the Interdependence Between US Monetary Policy and the Stock Market. Journal of Monetary Economics 56 (2), 275-282.

Blanchard, O., Simon, J., 2001. The Long and Large Decline in U.S. Output Volatility. Brookings Papers on Economic Activity 32 (1), 135-174.

Bubák, V., Kočenda, E., Žikeš, F., 2011. Volatility Transmission in Emerging European foreign Exchange Markets. Journal of Banking $\mathcal{E}$ Finance 35 (11), 2829-2841.

Caballero, R., H. M., 1991. The Cleansing Effect of Recessions. American Economic Review 84 (5), 1350-1368.

Caporale, T., McKiernan, B., 1996. The Relationship between Output Variability and Growth: Evidence from Post War UK Data. Scottish Journal of Political Economy 43 (2), 229-36.

Caporale, T., McKiernan, B., 1998. The Fischer Black Hypothesis: Some Time-Series Evidence. Southern Economic Journal 64 (3), 765-771.

Carare, A., Mody, A., 2012. Spillovers of Domestic Shocks: Will They Counteract the Great Moderation? International Finance 15 (1), 69-97.

Diebold, F. X., Yilmaz, K., 2009. Measuring Financial Asset Return and Volatility Spillovers, with Application to Global Equity Markets. Economic Journal 119 (534), 158-171.

Diebold, F. X., Yilmaz, K., 2012. Better to Give than to Receive: Predictive Directional Measurement of Volatility Spillovers. International Journal of Forecasting 28 (1), 57-66.

Döpke, J., 2004. How Robust is the Empirical Link between Business-Cycle Volatility and LongRun Growth in OECD Countries? International Review of Applied Economics 18 (1), 1-23.

Eickmeier, S., Lemke, W., Marcellino, M., 2011. The Changing International Transmission of Financial Shocks: Evidence from a Classical Time-Varying FAVAR. Discussion Paper Series 1: Economic Studies 05, Deutsche Bundesbank, Research Centre. 
Espinoza, R., Fornari, F., Lombardi, M. J., 2012. The Role of Financial Variables in Predicting Economic Activity. Journal of Forecasting 31 (1), 15-46.

Fatás, A., 2002. The Effects of Bussiness Cycles on Growth. In: Loayza, N., Soto, R., Loayza, N., Schmidt-Hebbel, K. (Eds.), Economic Growth: Sources, Trends, and Cycles. Vol. 6 of Central Banking, Analysis, and Economic Policies Book Series. Central Bank of Chile, Ch. 7, pp. 191-220.

Fatás, A., Mihov, I., 2003. The Case For Restricting Fiscal Policy Discretion. The Quarterly Journal of Economics 118 (4), 1419-1447.

Fountas, S., Karanasos, M., 2006. The Relationship Between Economic Growth and Real Uncertainty in the G3. Economic Modelling 23 (4), 638-647.

Fountas, S., Karanasos, M., Mendoza, A., 2004. Output Variability and Economic Growth: the Japanese Case. Bulletin of Economic Research 56 (4), 353-363.

Grier, K. B., Tullock, G., 1989. An Empirical Analysis of Cross-National Economic Growth, 1951-1980. Journal of Monetary Economics 24 (2), 259-276.

Imbs, J., 2007. Growth and Volatility. Journal of Monetary Economics 54 (7), 1848-1862.

Imbs, J., 2010. The First Global Recession in Decades. IMF Economic Review 58 (2), 327-354.

Kodama, M., 2014. Does Growth Affect Volatility? An Empirical Study on Developing Countries. Applied Economics Letters 21 (4), 257-260.

Koop, G., Pesaran, M. H., Potter, S. M., 1996. Impulse Response Analysis in Nonlinear Multivariate Models. Journal of Econometrics 74 (1), 119-147.

Kormendi, R. C., Meguire, P. G., 1985. Macroeconomic Determinants of Growth: Cross-country Evidence. Journal of Monetary Economics 16 (2), 141-163.

Kose, M. A., Otrok, C., Whiteman, C. H., 2003. International Business Cycles: World, Region, and Country-Specific Factors. American Economic Review 93 (4), 1216-1239.

Kose, M. A., Prasad, E. S., Terrones, M. E., 2005. Growth and Volatility in an Era of Globalization. IMF Staff Papers 52 (4), 31-63.

Laopodis, N. T., 2009. Are Fundamentals still Relevant for European Economies in the PostEuro Period? Economic Modelling 26 (5), 835-850.

Lee, J., 2010. The Link Between Output Growth and Volatility: Evidence from a GARCH Model with Panel Data. Economics Letters 106 (2), 143-145.

Lensink, R., Bo, H., Sterken, E., 1999. Does Uncertainty Affect Economic Growth? An Empirical Analysis. Review of World Economics (Weltwirtschaftliches Archiv) 135 (3), 379-396.

Martin, P., Ann Rogers, C., 2000. Long-term Growth and Short-term Economic Instability. European Economic Review 44 (2), 359-381.

McMillan, D. G., Speight, A. E., 2010. Return and Volatility Spillovers in Three Euro Exchange Rates. Journal of Economics and Business 62 (2), 79-93.

Mirman, L. J., 1971. Uncertainty and Optimal Consumption Decisions. Econometrica 39 (1), 179-85. 
Narayan, P. K., Narayan, S., Prabheesh, K. P., 2014. Stock Returns, Mutual Fund Flows and Spillover Shocks. Pacific-Basin Finance Journal 29, 146-162.

Norrbin, S. C., Yigit, F. P., 2005. The Robustness of the Link between Volatility and Growth of Output. Review of World Economics (Weltwirtschaftliches Archiv) 141 (2), 343-356.

Peersman, G., Van Robays, I., 2012. Cross-Country Differences in the Effects of Oil Shocks. Energy Economics 34 (5), 1532-1547.

Pesaran, H. H., Shin, Y., 1998. Generalized Impulse Response Analysis in Linear Multivariate Models. Economics Letters 58 (1), 17-29.

Posch, O., Wälde, K., 2011. On the Link Between Volatility and Growth. Journal of Economic Growth 16 (4), 285-308.

Qu, Z., Perron, P., 2007. Estimating and Testing Structural Changes in Multivariate Regressions. Econometrica 2 (75), 459-502.

Rafferty, M., 2005. The Effects of Expected and Unexpected Volatility on Long-Run Growth: Evidence from 18 Developed Economies. Southern Economic Journal 71 (3), 582-591.

Ramey, G., Ramey, V. A., 1995. Cross-Country Evidence on the Link between Volatility and Growth. American Economic Review 85 (5), 1138-51.

Sims, C., 1980. Macroeconomics and Reality. Econometrica 48, 1-48.

Stiglitz, J. E., 1993. Endogenous Growth and Cycles. NBER Working Papers 4286, National Bureau of Economic Research, Inc.

Yilmaz, K., Mar. 2009. International Business Cycle Spillovers. Koç University-TUSIAD Economic Research Forum Working Papers 0903, Koc University-TUSIAD Economic Research Forum.

Yilmaz, K., 2010. Return and volatility spillovers among the East Asian equity markets. Journal of Asian Economics 21 (3), 304-313.

Zhou, X., Zhang, W., Zhang, J., 2012. Volatility Spillovers between the Chinese and World Equity Markets. Pacific-Basin Finance Journal 20 (2), 247-270. 
Figure 1: Total spillover index (1985M11-2013M8

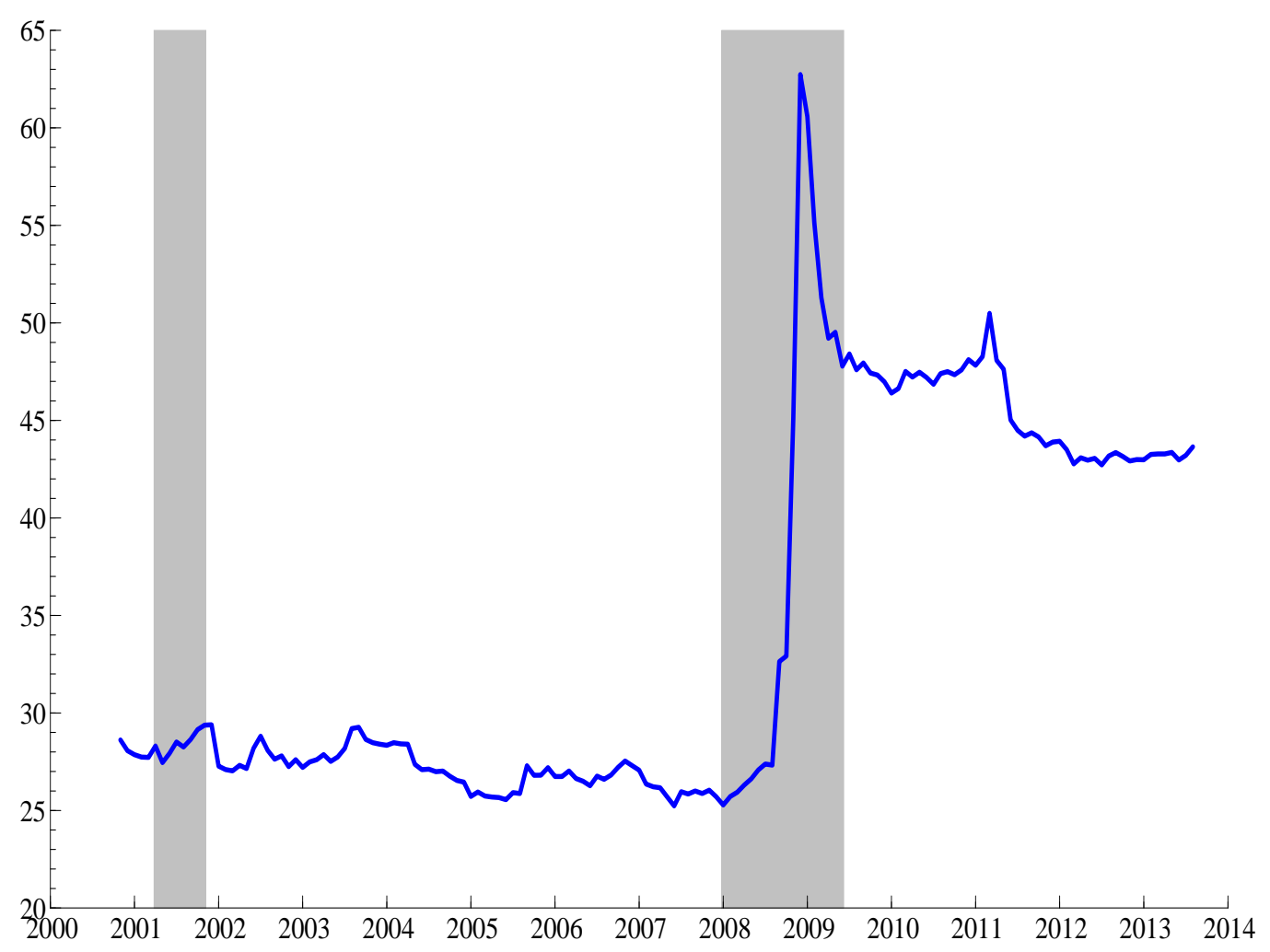

Note: Plots of moving total spillover index estimated using 180-month rolling windows. Gray shading denotes US recessions as defined by NBER. 
Figure 2: Directional spillovers from each countries' output growth and volatility (1985M112013M8)
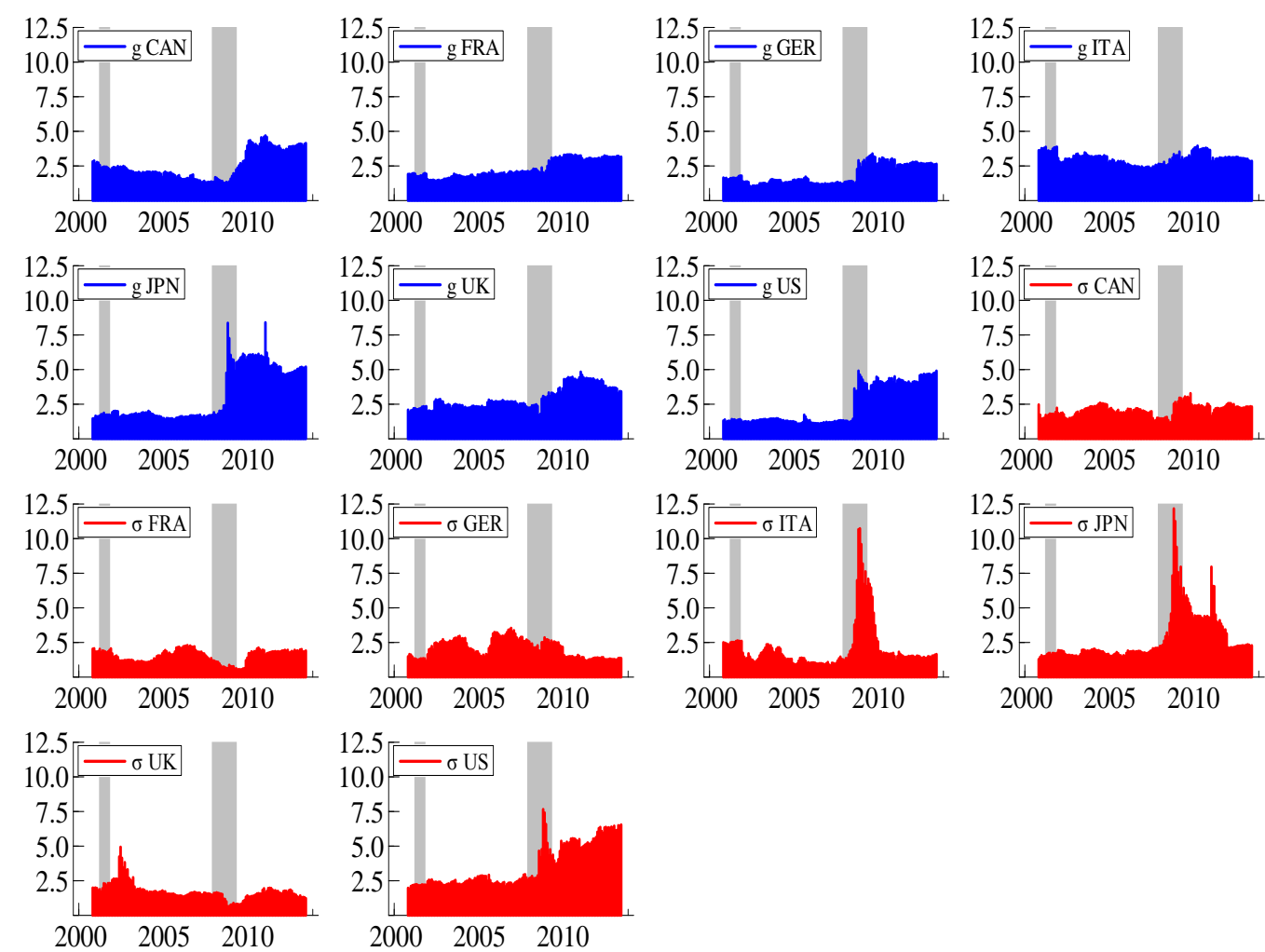

Note: Plots of moving directional spillovers estimated using 180-month rolling windows. Blue bars indicate output growth; red bars indicate output volatility. Gray shading denotes US recessions as defined by NBER. 
Figure 3: Generalized impulse responses to US shocks (1985M11-2013M8)

a) Responses to shocks to g US
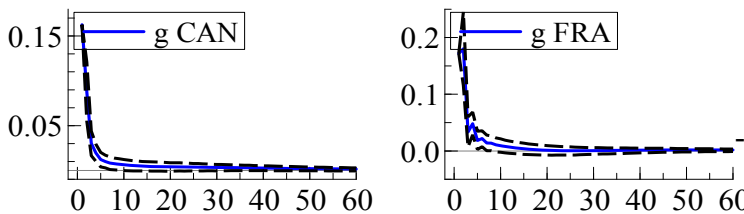

b) Responses to shocks to $\sigma$ US
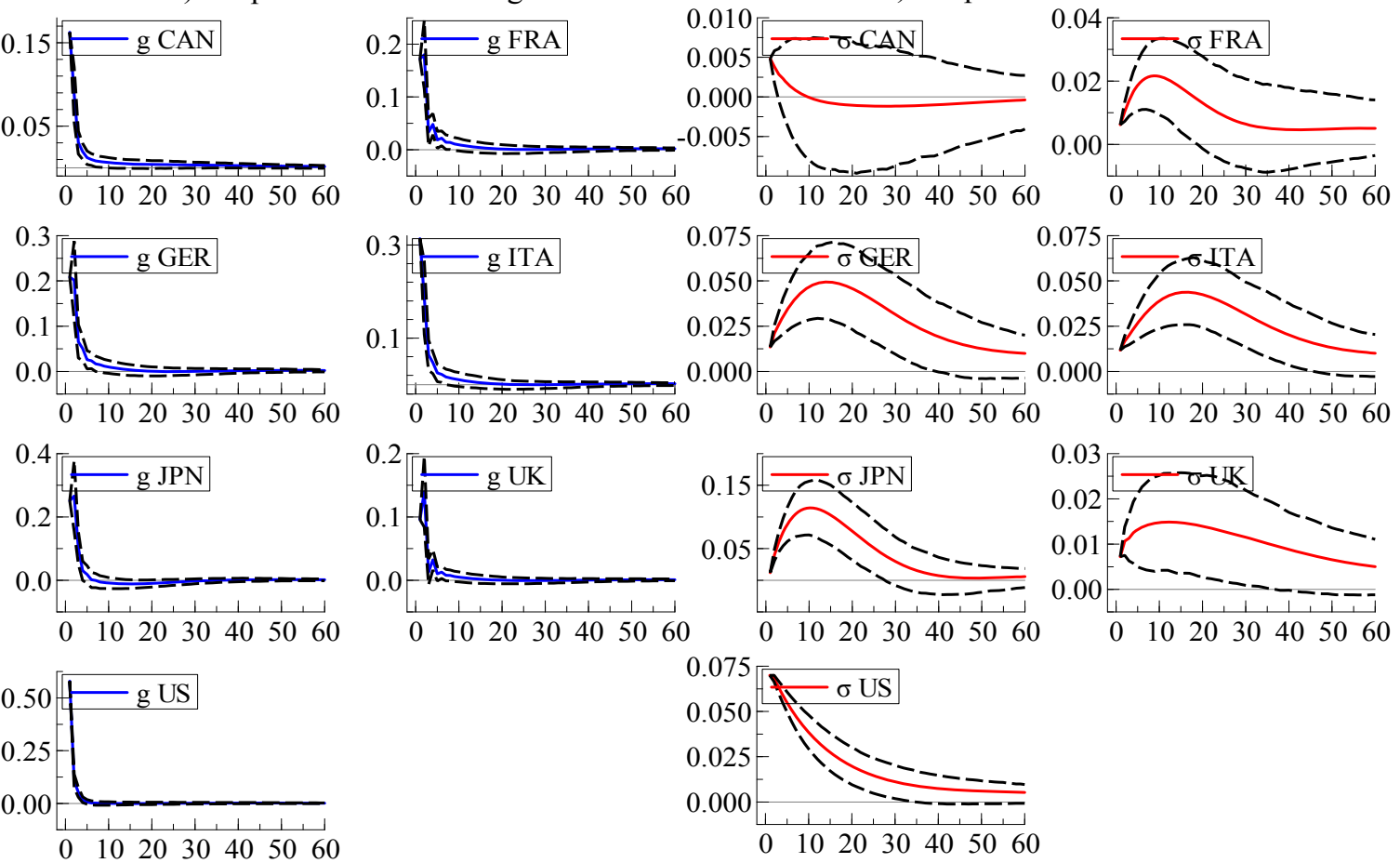

c) Responses to shocks to $\sigma$ US
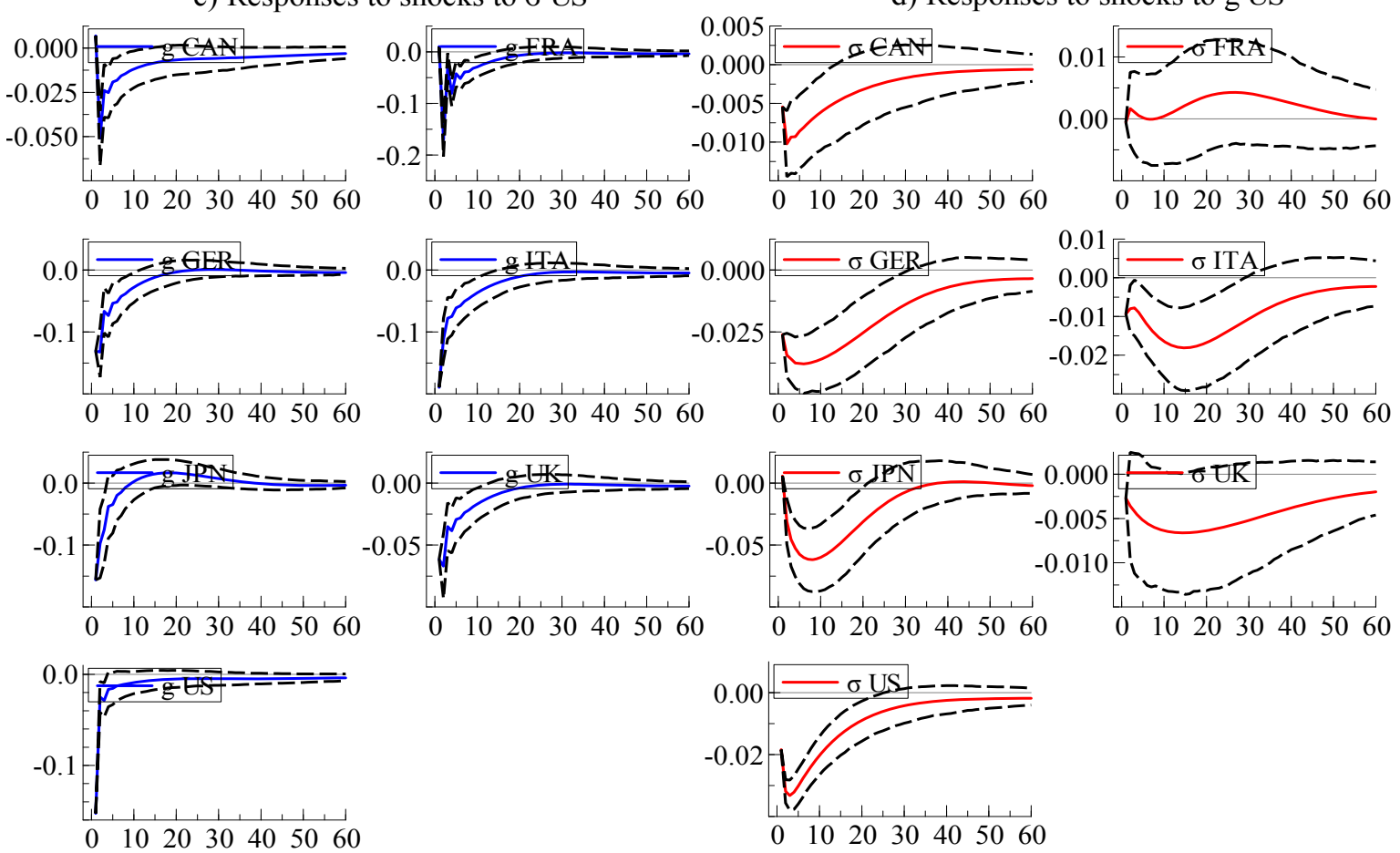

Note: Generalized impulse responses to one standard deviation shock to output growth (output volatility) of the US. Blue lines indicate responses of output growth; red lines indicate responses of output volatility. Dashed lines are the $95 \%$ upper and lower error bands based on Monte Carlo simulation with 1000 draws. 

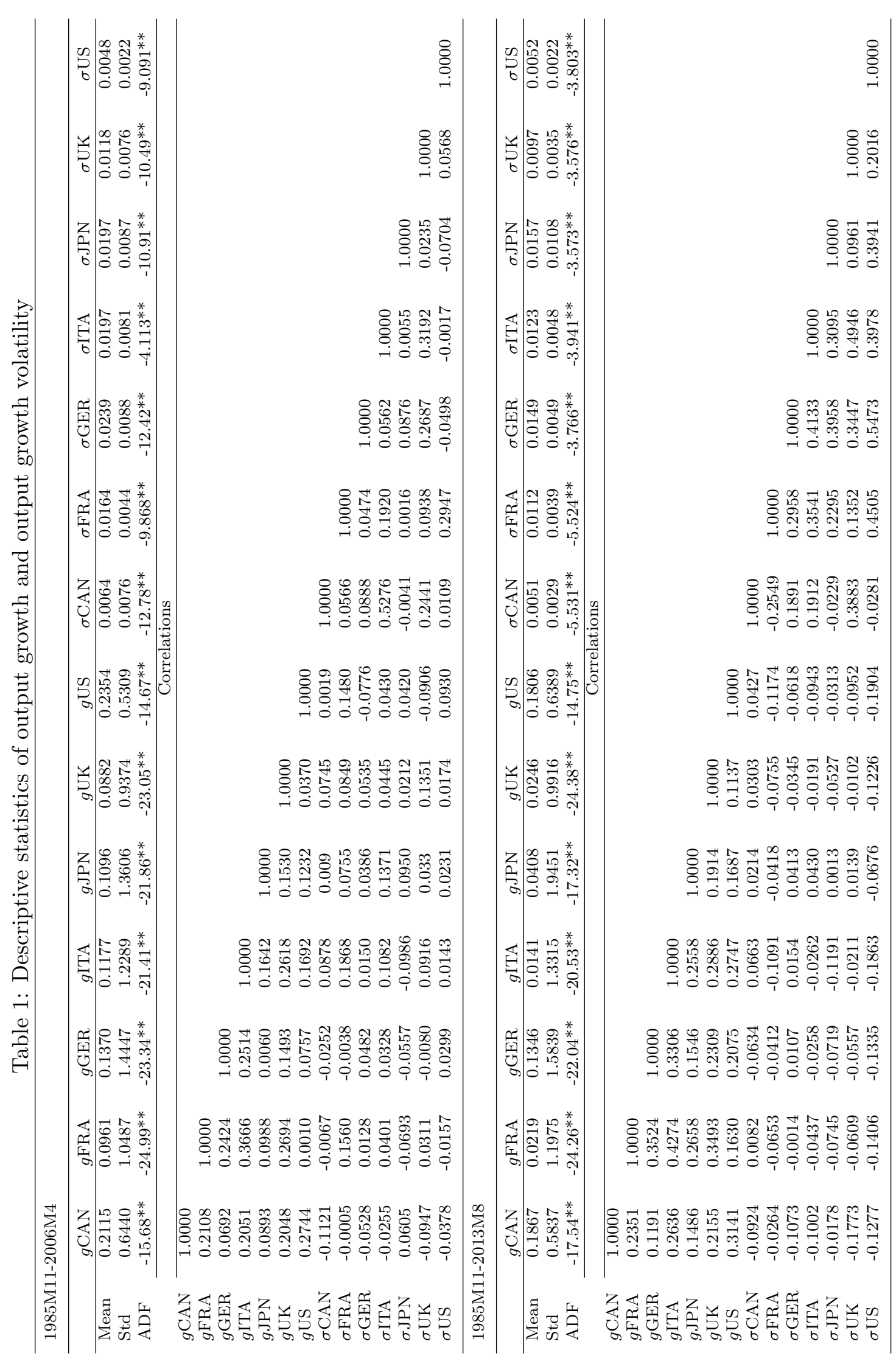

递

$\approx$

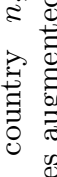

$\nexists$

훈 항

品是

호

U.

品

స]

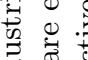

चี के

40

흘

뭉

สิ

武

용

函

담

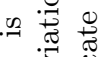

6

$\therefore$ 范 *

焉焉

范

पै

蛋玄

的 I

न क

获需

之

至

预

5

넝응

↔ 表

का 它记 
Table 2: Structural break analysis based on Qu and Perron (2007) test

\begin{tabular}{|c|c|c|c|c|}
\hline \multirow[b]{3}{*}{ Full model } & \multirow[b]{2}{*}{$W d_{\max }$} & \multicolumn{2}{|c|}{ Sequential test $(l+1 / l)$} & \multirow[b]{2}{*}{ Number of breaks } \\
\hline & & $l=1$ & $l=2$ & \\
\hline & $155.142^{* * *}$ & $49.199^{* * *}$ & $54.747^{* * *}$ & 3 \\
\hline & \multicolumn{4}{|c|}{ Estimated breaks } \\
\hline
\end{tabular}

Notes: (i) $M=3$ for the full sample. (ii) Trimming=0.20. (iii) $T=667$ (1958M2-2013M8). (iv) The covariance matrix of the errors is allowed to change. (v) Serial correlation in the residuals is corrected and the robust covariance matrix is constructed by the method of Andrews (1991), however, no pre-whitening technique is applied. 


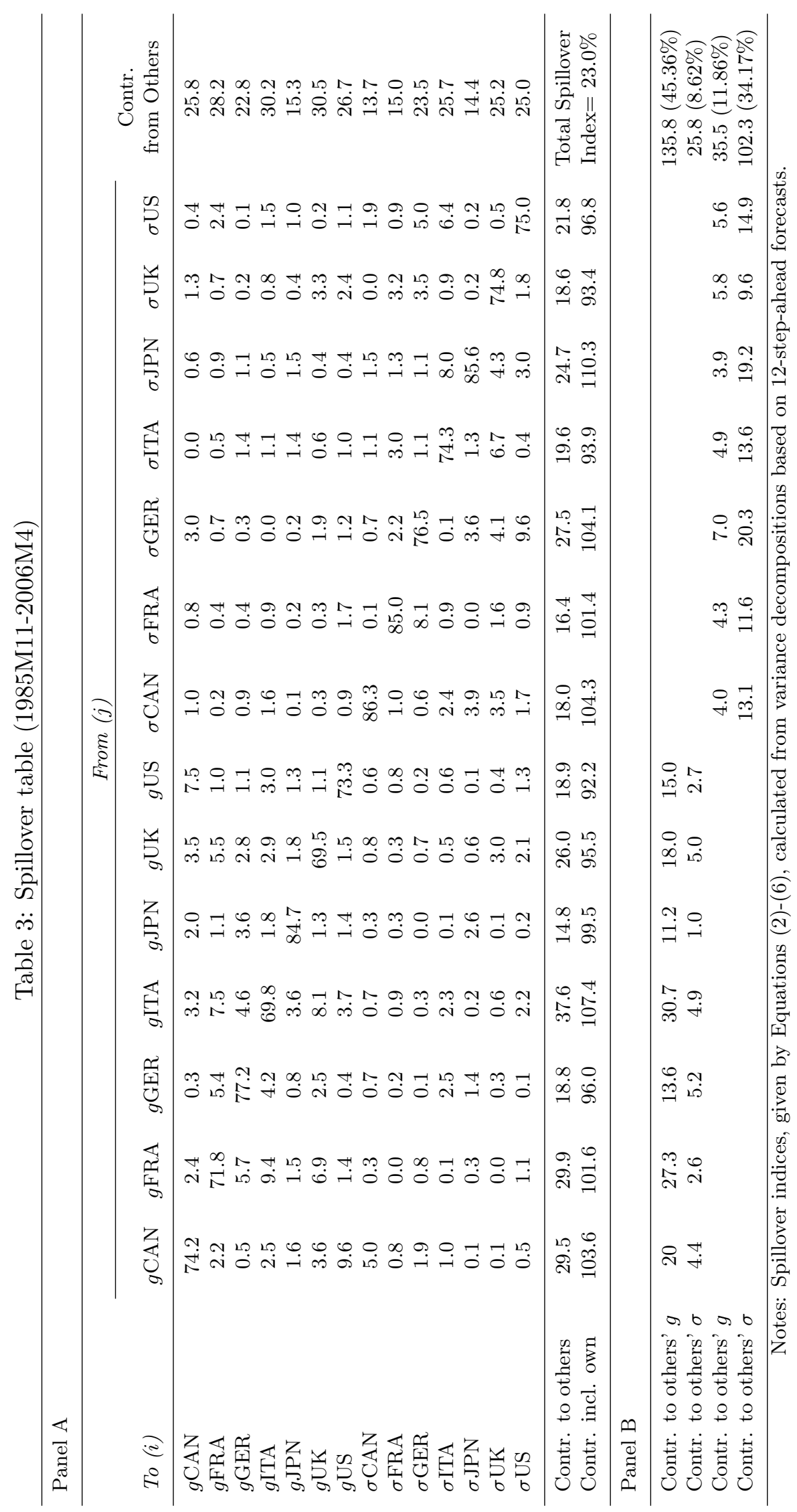




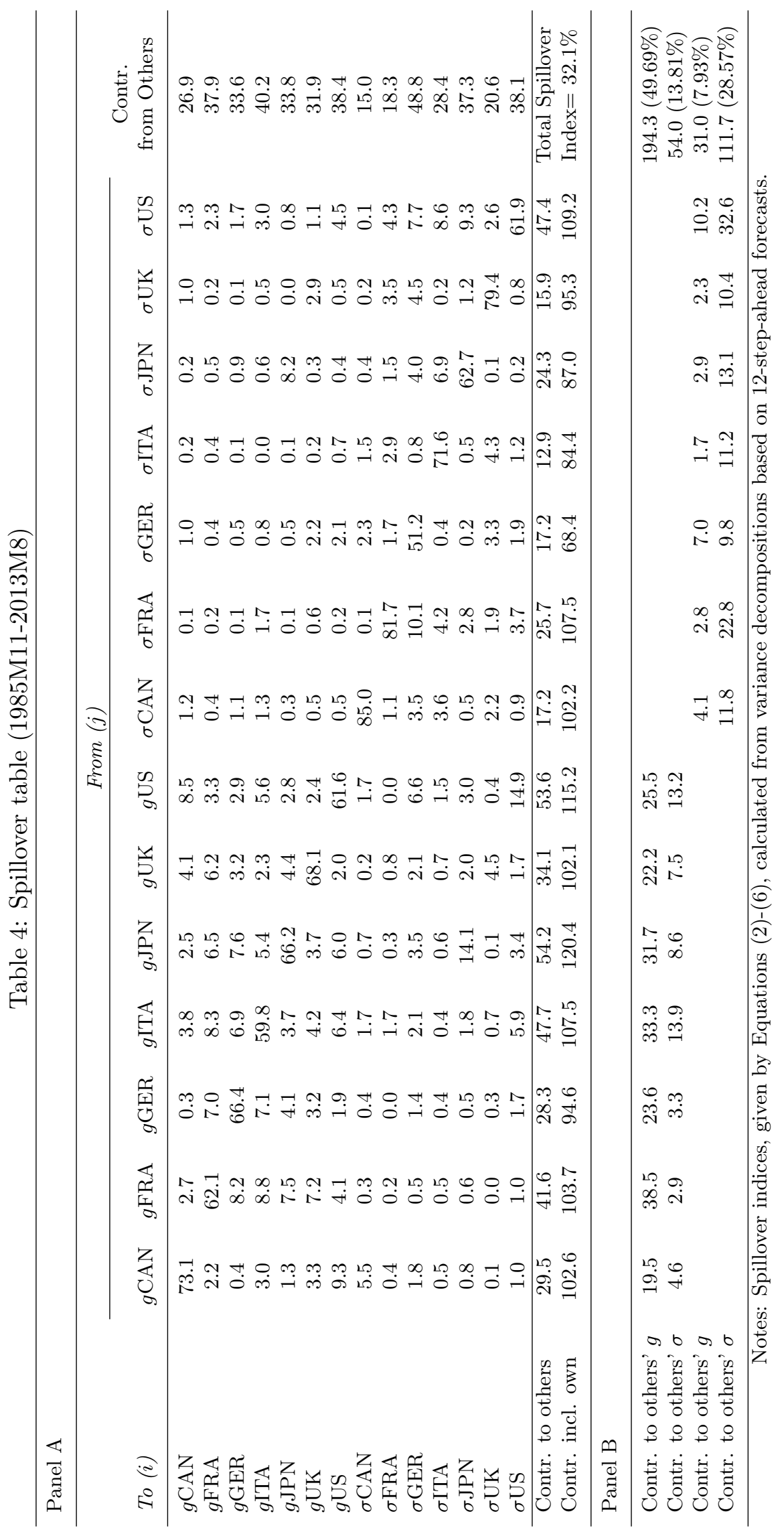


Table 5: Cumulative impulse responses and multiplier effects (1985M11-2013M8)

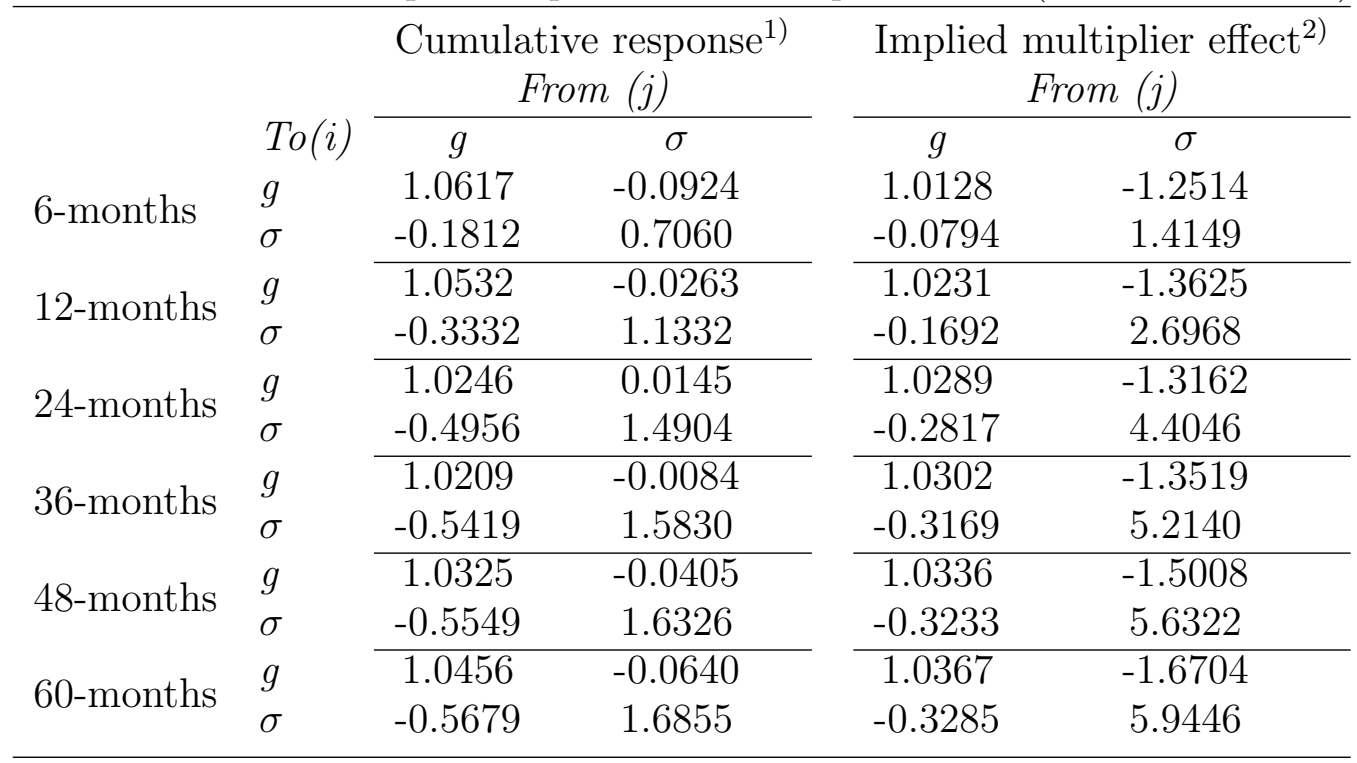

Notes: ${ }^{1)}$ Cumulative generalized impulse response to one standard deviation shock, multiplied by 100 (in \%).

2) Multiplier effect, calculated as ratio of cumulative response to incipient shock to the respective country.

All entries are averages over country-specific shocks to the respective variable.

\section{Appendix}


Table A.1: Generalized forecast error variance decomposition approach (1985M11-2013M8)

\begin{tabular}{|c|c|c|c|c|c|c|c|c|c|c|c|c|c|c|}
\hline Variance & ecompos & on of $g$ & & & & & & & & & & & & \\
\hline Horizon & $g$ CAN & $g$ FRA & $g$ GER & $g$ ITA & $g$ JPN & $g$ UK & $g$ US & $\sigma \mathrm{CAN}$ & $\sigma$ FRA & $\sigma$ GER & $\sigma$ ITA & $\sigma \mathrm{JPN}$ & $\sigma \mathrm{UK}$ & $\sigma \mathrm{US}$ \\
\hline 1 & 79.188 & 2.676 & 0.139 & 3.902 & 1.227 & 3.557 & 6.796 & 1.181 & 0.120 & 0.925 & 0.005 & 0.025 & 0.247 & 0.012 \\
\hline 3 & 74.361 & 2.773 & 0.266 & 3.834 & 2.518 & 4.059 & 8.429 & 1.140 & 0.134 & 0.998 & 0.063 & 0.079 & 0.572 & 0.774 \\
\hline 6 & 73.621 & 2.758 & 0.278 & 3.825 & 2.513 & 4.072 & 8.474 & 1.145 & 0.142 & 0.992 & 0.118 & 0.146 & 0.841 & 1.074 \\
\hline 12 & 73.059 & 2.741 & 0.285 & 3.812 & 2.495 & 4.058 & 8.461 & 1.173 & 0.148 & 0.988 & 0.250 & 0.221 & 1.035 & 1.276 \\
\hline Variance & ecompos & on of $g \mathrm{~F}$ & & & & & & & & & & & & \\
\hline Horizon & $g$ CAN & $g$ FRA & $g$ GER & $g$ ITA & $g \mathrm{JPN}$ & $g$ UK & $g$ US & $\sigma \mathrm{CAN}$ & $\sigma$ FRA & $\sigma$ GER & $\sigma$ ITA & $\sigma \mathrm{JPN}$ & $\sigma \mathrm{UK}$ & $\sigma \mathrm{US}$ \\
\hline 1 & 2.169 & 64.202 & 8.146 & 9.419 & 6.142 & 7.068 & 1.762 & 0.485 & 0.154 & 0.048 & 0.386 & 0.000 & 0.012 & 0.006 \\
\hline 3 & 2.255 & 62.927 & 7.127 & 8.437 & 6.551 & 6.275 & 3.239 & 0.425 & 0.150 & 0.101 & 0.366 & 0.511 & 0.099 & 1.538 \\
\hline 6 & 2.243 & 62.444 & 7.051 & 8.342 & 6.491 & 6.196 & 3.329 & 0.421 & 0.150 & 0.233 & 0.362 & 0.514 & 0.170 & 2.054 \\
\hline 12 & 2.230 & 62.081 & 7.011 & 8.312 & 6.456 & 6.166 & 3.339 & 0.429 & 0.152 & 0.369 & 0.362 & 0.550 & 0.222 & 2.320 \\
\hline Variance & ecompos & on of $g C$ & & & & & & & & & & & & \\
\hline Horizon & $g$ CAN & $g$ FRA & $g$ GER & $g$ ITA & $g \mathrm{JPN}$ & $g$ UK & $g$ US & $\sigma \mathrm{CAN}$ & $\sigma$ FRA & $\sigma$ GER & $\sigma$ ITA & $\sigma \mathrm{JPN}$ & $\sigma \mathrm{UK}$ & $\sigma \mathrm{US}$ \\
\hline 1 & 0.128 & 9.236 & 72.793 & 7.812 & 2.662 & 3.422 & 1.576 & 1.179 & 0.111 & 0.170 & 0.062 & 0.123 & 0.105 & 0.623 \\
\hline 3 & 0.348 & 8.290 & 67.213 & 6.965 & 7.536 & 3.191 & 2.778 & 1.122 & 0.101 & 0.204 & 0.065 & 0.848 & 0.107 & 1.231 \\
\hline 6 & 0.356 & 8.219 & 66.635 & 6.930 & 7.638 & 3.172 & 2.851 & 1.139 & 0.102 & 0.360 & 0.065 & 0.861 & 0.122 & 1.549 \\
\hline 12 & 0.355 & 8.187 & 66.359 & 6.918 & 7.608 & 3.162 & 2.860 & 1.141 & 0.106 & 0.481 & 0.065 & 0.903 & 0.138 & 1.715 \\
\hline Variance & ecompos & on of $g \mathrm{I}$ & & & & & & & & & & & & \\
\hline Horizon & $g$ CAN & $g$ FRA & $g$ GER & $g$ ITA & $g$ JPN & $g$ UK & $g$ US & $\sigma \mathrm{CAN}$ & $\sigma$ FRA & $\sigma$ GER & $\sigma$ ITA & $\sigma \mathrm{JPN}$ & $\sigma \mathrm{UK}$ & $\sigma$ US \\
\hline 1 & 3.189 & 9.494 & 6.945 & 64.715 & 3.509 & 2.270 & 4.463 & 1.344 & 1.768 & 0.128 & 0.000 & 0.043 & 0.502 & 1.628 \\
\hline 3 & 3.049 & 8.914 & 7.147 & 60.958 & 5.431 & 2.300 & 5.615 & 1.236 & 1.766 & 0.218 & 0.029 & 0.620 & 0.490 & 2.225 \\
\hline 6 & 3.013 & 8.832 & 7.175 & 60.253 & 5.423 & 2.287 & 5.663 & 1.257 & 1.754 & 0.488 & 0.033 & 0.634 & 0.492 & 2.694 \\
\hline 12 & 2.995 & 8.765 & 7.119 & 59.785 & 5.389 & 2.275 & 5.645 & 1.319 & 1.745 & 0.767 & 0.037 & 0.639 & 0.500 & 3.021 \\
\hline Variance & ecompos & on of $g \mathrm{~J}$ & & & & & & & & & & & & \\
\hline Horizon & $g$ CAN & $g$ FRA & $g$ GER & $g$ ITA & $g \mathrm{JPN}$ & $g$ UK & $g$ US & $\sigma \mathrm{CAN}$ & $\sigma$ FRA & $\sigma$ GER & $\sigma$ ITA & $\sigma \mathrm{JPN}$ & $\sigma \mathrm{UK}$ & $\sigma \mathrm{US}$ \\
\hline 1 & 1.113 & 6.876 & 2.629 & 3.897 & 71.872 & 3.234 & 1.322 & 0.295 & 0.120 & 0.331 & 0.034 & 7.761 & 0.005 & 0.511 \\
\hline 3 & 1.283 & 7.579 & 4.094 & 3.758 & 67.038 & 4.420 & 2.798 & 0.296 & 0.112 & 0.366 & 0.054 & 7.407 & 0.024 & 0.769 \\
\hline 6 & 1.292 & 7.568 & 4.100 & 3.750 & 66.585 & 4.428 & 2.795 & 0.308 & 0.112 & 0.413 & 0.054 & 7.752 & 0.026 & 0.817 \\
\hline 12 & 1.297 & 7.511 & 4.071 & 3.726 & 66.161 & 4.406 & 2.783 & 0.346 & 0.120 & 0.452 & 0.060 & 8.215 & 0.033 & 0.819 \\
\hline Variance & ecompos & on of $g$ L & & & & & & & & & & & & \\
\hline Horizon & $g$ CAN & $g$ FRA & $g$ GER & $g$ ITA & $g \mathrm{JPN}$ & $g$ UK & $g$ US & $\sigma \mathrm{CAN}$ & $\sigma$ FRA & $\sigma$ GER & $\sigma$ ITA & $\sigma \mathrm{JPN}$ & $\sigma \mathrm{UK}$ & $\sigma \mathrm{US}$ \\
\hline 1 & 3.251 & 7.967 & 3.402 & 2.538 & 3.257 & 72.370 & 0.844 & 0.526 & 0.422 & 2.100 & 0.233 & 0.021 & 2.721 & 0.349 \\
\hline 3 & 3.346 & 7.228 & 3.127 & 4.100 & 3.721 & 68.867 & 2.308 & 0.502 & 0.573 & 2.032 & 0.207 & 0.275 & 2.956 & 0.758 \\
\hline 6 & 3.343 & 7.190 & 3.212 & 4.237 & 3.708 & 68.304 & 2.377 & 0.504 & 0.580 & 2.117 & 0.207 & 0.277 & 2.953 & 0.990 \\
\hline 12 & 3.333 & 7.169 & 3.205 & 4.237 & 3.699 & 68.079 & 2.383 & 0.521 & 0.581 & 2.196 & 0.208 & 0.305 & 2.946 & 1.137 \\
\hline Variance & ecompos & on of $g$ L & & & & & & & & & & & & \\
\hline Horizon & $g$ CAN & $g$ FRA & $g$ GER & $g$ ITA & $g$ JPN & $g \mathrm{UK}$ & $g$ US & $\sigma \mathrm{CAN}$ & $\sigma$ FRA & $\sigma$ GER & $\sigma$ ITA & $\sigma \mathrm{JPN}$ & $\sigma \mathrm{UK}$ & $\sigma$ US \\
\hline 1 & 6.383 & 2.041 & 1.611 & 5.130 & 1.368 & 0.868 & 74.380 & 0.315 & 0.002 & 2.218 & 0.464 & 0.022 & 0.045 & 5.156 \\
\hline 3 & 9.434 & 4.076 & 1.873 & 6.425 & 5.990 & 1.962 & 62.477 & 0.323 & 0.130 & 1.908 & 0.427 & 0.299 & 0.264 & 4.412 \\
\hline 6 & 9.377 & 4.098 & 1.866 & 6.415 & 5.987 & 1.974 & 62.042 & 0.394 & 0.151 & 1.954 & 0.490 & 0.344 & 0.422 & 4.486 \\
\hline 12 & 9.344 & 4.067 & 1.852 & 6.367 & 5.968 & 1.963 & 61.573 & 0.480 & 0.161 & 2.063 & 0.653 & 0.447 & 0.536 & 4.525 \\
\hline Variance & ecompos & on of $\sigma$ & & & & & & & & & & & & \\
\hline Horizon & $g$ CAN & $g$ FRA & $g$ GER & $g$ ITA & $g \mathrm{JPN}$ & $g$ UK & $g$ US & $\sigma \mathrm{CAN}$ & $\sigma$ FRA & $\sigma$ GER & $\sigma$ ITA & $\sigma \mathrm{JPN}$ & $\sigma$ UK & $\sigma \mathrm{US}$ \\
\hline 1 & 1.331 & 0.674 & 1.445 & 1.854 & 0.367 & 0.649 & 0.378 & 89.251 & 0.048 & 0.019 & 3.408 & 0.262 & 0.015 & 0.301 \\
\hline 3 & 3.709 & 0.418 & 0.623 & 1.605 & 0.389 & 0.310 & 1.130 & 88.474 & 0.039 & 0.210 & 2.525 & 0.319 & 0.015 & 0.236 \\
\hline 6 & 4.692 & 0.372 & 0.454 & 1.629 & 0.498 & 0.217 & 1.442 & 87.459 & 0.048 & 0.818 & 1.788 & 0.354 & 0.046 & 0.181 \\
\hline 12 & 5.458 & 0.348 & 0.394 & 1.698 & 0.664 & 0.195 & 1.651 & 84.988 & 0.076 & 2.341 & 1.510 & 0.370 & 0.170 & 0.138 \\
\hline Varianc & ecompos & on of $\sigma \mathrm{I}$ & & & & & & & & & & & & \\
\hline Horizon & $g$ CAN & $g$ FRA & $g$ GER & $g$ ITA & $g \mathrm{JPN}$ & $g$ UK & $g$ US & $\sigma \mathrm{CAN}$ & $\sigma$ FRA & $\sigma$ GER & $\sigma$ ITA & $\sigma \mathrm{JPN}$ & $\sigma$ UK & $\sigma \mathrm{US}$ \\
\hline 1 & 0.133 & 0.210 & 0.134 & 2.401 & 0.147 & 0.512 & 0.002 & 0.047 & 87.886 & 4.118 & 1.198 & 0.626 & 2.296 & 0.290 \\
\hline 3 & 0.061 & 0.221 & 0.060 & 1.816 & 0.488 & 0.803 & 0.013 & 0.037 & 88.163 & 2.771 & 1.432 & 0.487 & 2.699 & 0.950 \\
\hline 6 & 0.107 & 0.220 & 0.040 & 1.807 & 0.393 & 0.862 & 0.008 & 0.215 & 87.088 & 1.714 & 1.830 & 0.346 & 3.121 & 2.250 \\
\hline 12 & 0.378 & 0.200 & 0.027 & 1.740 & 0.292 & 0.813 & 0.009 & 1.051 & 81.746 & 1.654 & 2.880 & 1.471 & 3.467 & 4.271 \\
\hline Variance & ecompos & on of $\sigma$ & $\mathrm{R}$ & & & & & & & & & & & \\
\hline Horizon & $g$ CAN & $g$ FRA & $g$ GER & $g$ ITA & $g$ JPN & $g$ UK & $g$ US & $\sigma \mathrm{CAN}$ & $\sigma$ FRA & $\sigma$ GER & $\sigma$ ITA & $\sigma \mathrm{JPN}$ & $\sigma \mathrm{UK}$ & $\sigma \mathrm{US}$ \\
\hline 1 & 0.968 & 0.062 & 0.193 & 0.164 & 0.382 & 2.403 & 2.469 & 0.017 & 3.881 & 82.828 & 0.010 & 0.330 & 5.638 & 0.656 \\
\hline 3 & 1.189 & 0.158 & 1.032 & 0.613 & 1.239 & 1.725 & 4.197 & 0.560 & 5.038 & 76.135 & 0.145 & 1.244 & 4.984 & 1.742 \\
\hline 6 & 1.541 & 0.318 & 1.313 & 1.177 & 2.267 & 1.858 & 5.463 & 1.746 & 6.856 & 66.169 & 0.426 & 2.577 & 4.656 & 3.631 \\
\hline 12 & 1.829 & 0.540 & 1.432 & 2.140 & 3.501 & 2.137 & 6.648 & 3.489 & 10.113 & 51.221 & 0.780 & 3.996 & 4.505 & 7.669 \\
\hline Varian & ecompos & on of $\sigma \mathrm{I}$ & & & & & & & & & & & & \\
\hline Horizon & $g$ CAN & $g$ FRA & $g$ GER & $g$ ITA & $g \mathrm{JPN}$ & $g$ UK & $g$ US & $\sigma \mathrm{CAN}$ & $\sigma$ FRA & $\sigma$ GER & $\sigma$ ITA & $\sigma \mathrm{JPN}$ & $\sigma \mathrm{UK}$ & $\sigma \mathrm{US}$ \\
\hline 1 & 0.006 & 0.553 & 0.078 & 0.001 & 0.043 & 0.296 & 0.573 & 3.508 & 1.252 & 0.011 & 91.877 & 0.825 & 0.083 & 0.894 \\
\hline 3 & 0.714 & 0.350 & 0.204 & 0.035 & 0.282 & 0.289 & 0.493 & 3.449 & 1.564 & 0.032 & 89.046 & 1.557 & 0.084 & 1.901 \\
\hline 6 & 0.705 & 0.341 & 0.251 & 0.044 & 0.182 & 0.367 & 0.702 & 3.651 & 2.347 & 0.124 & 83.792 & 3.578 & 0.099 & 3.817 \\
\hline 12 & 0.491 & 0.467 & 0.369 & 0.360 & 0.606 & 0.681 & 1.518 & 3.614 & 4.175 & 0.402 & 71.567 & 6.923 & 0.246 & 8.580 \\
\hline Var & ecompos & on of $\sigma \mathrm{J}$ & & & & & & & & & & & & \\
\hline Horizon & $g \mathrm{CAN}$ & $g$ FRA & $g$ GER & $g$ ITA & $g \mathrm{JPN}$ & $g$ UK & $g$ US & $\sigma \mathrm{CAN}$ & $\sigma$ FRA & $\sigma$ GER & $\sigma$ ITA & $\sigma \mathrm{JPN}$ & $\sigma \mathrm{UK}$ & $\sigma \mathrm{US}$ \\
\hline 1 & 0.028 & 0.000 & 0.148 & 0.059 & 9.500 & 0.025 & 0.025 & 0.258 & 0.627 & 0.350 & 0.790 & 87.973 & 0.107 & 0.109 \\
\hline 3 & 0.272 & 0.201 & 0.239 & 0.261 & 11.697 & 0.974 & 0.806 & 0.417 & 0.965 & 0.315 & 0.496 & 81.866 & 0.063 & 1.426 \\
\hline 6 & 0.569 & 0.390 & 0.369 & 0.821 & 13.325 & 1.499 & 1.799 & 0.530 & 1.587 & 0.186 & 0.289 & 74.217 & 0.312 & 4.107 \\
\hline 12 & 0.806 & 0.555 & 0.495 & 1.773 & 14.073 & 2.021 & 2.996 & 0.505 & 2.778 & 0.243 & 0.536 & 62.717 & 1.246 & 9.255 \\
\hline Var & ecompos & on of $\sigma$ I & & & & & & & & & & & & \\
\hline Horizon & $g$ CAN & $g$ FRA & $g$ GER & $g$ ITA & $g$ JPN & $g$ UK & $g$ US & $\sigma \mathrm{CAN}$ & $\sigma$ FRA & $\sigma$ GER & $\sigma$ ITA & $\sigma \mathrm{JPN}$ & $\sigma \mathrm{UK}$ & $\sigma \mathrm{US}$ \\
\hline 1 & 0.270 & 0.017 & 0.125 & 0.674 & 0.006 & 3.265 & 0.053 & 0.015 & 2.268 & 5.911 & 0.078 & 0.106 & 86.839 & 0.374 \\
\hline 3 & 0.126 & 0.016 & 0.231 & 0.531 & 0.047 & 4.308 & 0.105 & 0.210 & 2.080 & 5.160 & 0.554 & 0.069 & 85.737 & 0.825 \\
\hline 6 & 0.084 & 0.021 & 0.281 & 0.585 & 0.057 & 4.488 & 0.201 & 0.811 & 1.973 & 4.275 & 1.693 & 0.049 & 84.054 & 1.429 \\
\hline 12 & 0.061 & 0.050 & 0.338 & 0.706 & 0.076 & 4.493 & 0.427 & 2.229 & 1.871 & 3.322 & 4.307 & 0.055 & 79.428 & 2.636 \\
\hline Varia & ecompos & on of $\sigma$ L & & & & & & & & & & & & \\
\hline Horizon & $g$ CAN & $g$ FRA & $g$ GER & $g$ ITA & $g$ JPN & $g$ UK & $g$ US & $\sigma \mathrm{CAN}$ & $\sigma$ FRA & $\sigma$ GER & $\sigma$ ITA & $\sigma \mathrm{JPN}$ & $\sigma \mathrm{UK}$ & $\sigma \mathrm{US}$ \\
\hline 1 & 0.014 & 0.008 & 0.747 & 2.197 & 0.621 & 0.421 & 6.053 & 0.294 & 0.288 & 0.691 & 0.850 & 0.109 & 0.376 & 87.330 \\
\hline 3 & 0.543 & 0.526 & 1.347 & 4.794 & 2.507 & 1.110 & 12.969 & 0.614 & 0.807 & 1.386 & 0.862 & 0.142 & 0.429 & 71.964 \\
\hline 6 & 0.908 & 0.861 & 1.624 & 5.559 & 3.385 & 1.511 & 14.770 & 0.788 & 1.695 & 1.733 & 0.945 & 0.104 & 0.562 & 65.555 \\
\hline 12 & 0.973 & 0.996 & 1.682 & 5.914 & 3.378 & 1.689 & 14.860 & 0.873 & 3.687 & 1.880 & 1.228 & 0.159 & 0.826 & 61.854 \\
\hline
\end{tabular}

Note: Figures show the portion of a variable (in \%) that is explained by its own- and cross- innovative shocks. 


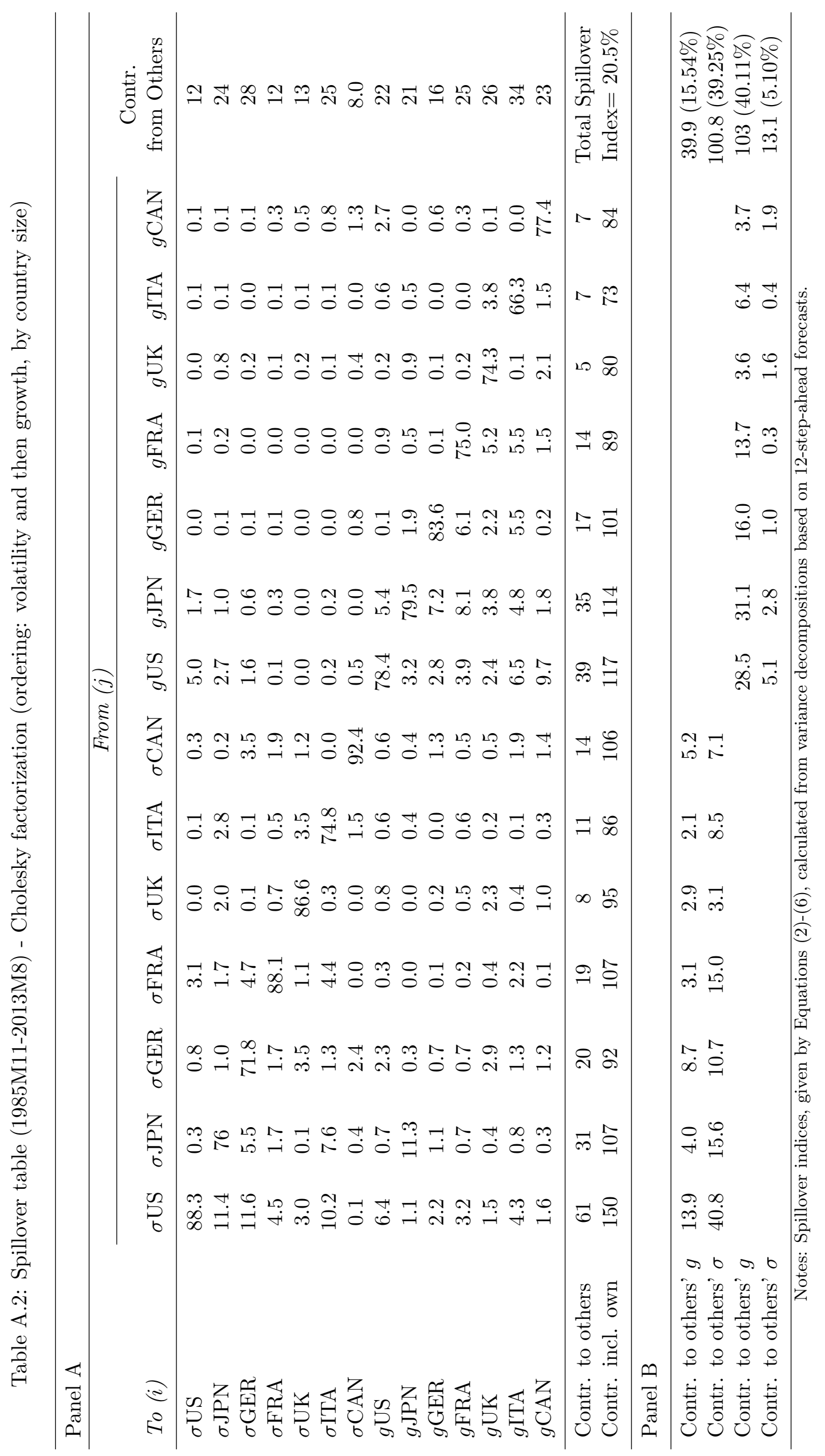


Table A.3: Cumulative impulse responses and multiplier effects (1985M11-2006M4)

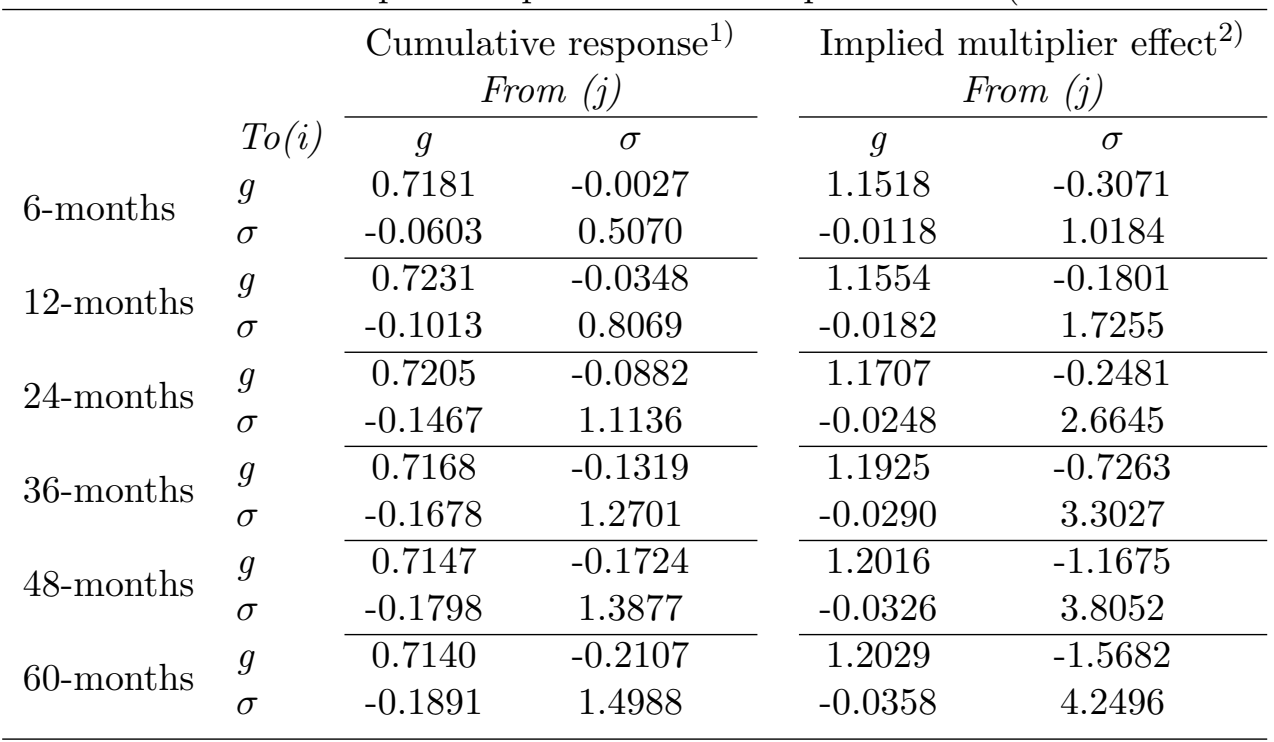

Notes: ${ }^{1)}$ Cumulative generalized impulse response to one standard deviation shock, multiplied by 100 (in \%).

2) Multiplier effect, calculated as ratio of cumulative response to incipient shock to the respective country.

All entries are averages over country-specific shocks to the respective variable.

Table A.4: Cumulative impulse responses and multiplier effects (1985M11-2013M8) - Cholesky factorization (ordering: volatility and then growth, by country size)

\begin{tabular}{|c|c|c|c|c|c|}
\hline & \multirow[b]{2}{*}{ To(i) } & \multicolumn{2}{|c|}{$\begin{array}{c}\text { Cumulative response }^{1)} \\
\text { From }(j)\end{array}$} & \multicolumn{2}{|c|}{$\begin{array}{l}\text { Implied multiplier effect }{ }^{2)} \\
\text { From }(j)\end{array}$} \\
\hline & & $g$ & $\sigma$ & $g$ & $\sigma$ \\
\hline \multirow{2}{*}{ 6-months } & $g$ & 0.8922 & -0.0428 & 1.1546 & -1.1844 \\
\hline & $\sigma$ & -0.0611 & 0.6852 & -0.0208 & 1.1336 \\
\hline \multirow{2}{*}{ 12-months } & $g$ & 0.8859 & -0.0894 & 1.4091 & -1.3782 \\
\hline & $\sigma$ & -0.0537 & 1.1273 & -0.0532 & 2.1780 \\
\hline \multirow{2}{*}{ 24-months } & $g$ & 0.8579 & -0.1443 & 1.6090 & -1.3883 \\
\hline & $\sigma$ & -0.1594 & 1.5154 & -0.0975 & 3.5799 \\
\hline \multirow{2}{*}{ 36-months } & $g$ & 0.8432 & -0.1564 & 1.6705 & -1.4333 \\
\hline & $\sigma$ & -0.1501 & 1.5690 & -0.1032 & 4.1440 \\
\hline \multirow{2}{*}{ 48-months } & $g$ & 0.8425 & -0.1502 & 1.7055 & -1.5940 \\
\hline & $\sigma$ & -0.1070 & 1.5447 & -0.0896 & 4.2828 \\
\hline \multirow{2}{*}{ 60-months } & $g$ & 0.8464 & -0.1434 & 1.7081 & -1.7602 \\
\hline & $\sigma$ & -0.0766 & 1.5409 & -0.0761 & 4.3209 \\
\hline
\end{tabular}

Notes: ${ }^{1)}$ Cumulative impulse response to one standard deviation shock based on Cholesky factorization, multiplied by 100 (in \%).

2) Multiplier effect, calculated as ratio of cumulative response to incipient shock to the respective country.

All entries are averages over country-specific shocks to the respective variable. 
Table A.5: Spillover table (1985M11-2013M8) - Only growth

\begin{tabular}{|c|c|c|c|c|c|c|c|c|}
\hline \multirow[b]{2}{*}{ To (i) } & \multicolumn{7}{|c|}{ From $(j)$} & \multirow{2}{*}{$\begin{array}{c}\text { Contr. } \\
\text { from Others }\end{array}$} \\
\hline & $g \mathrm{CAN}$ & $g \mathrm{FRA}$ & $g \mathrm{GER}$ & $g \mathrm{ITA}$ & $g \mathrm{JPN}$ & $g \mathrm{UK}$ & $g \mathrm{US}$ & \\
\hline$g \mathrm{CAN}$ & 77.9 & 3.0 & 0.5 & 3.4 & 2.6 & 3.5 & 9.1 & 22 \\
\hline$g \mathrm{FRA}$ & 2.2 & 62.7 & 8.7 & 10.0 & 5.5 & 6.8 & 4.1 & 37 \\
\hline$g \mathrm{GER}$ & 0.4 & 9.9 & 67.9 & 7.6 & 7.1 & 3.9 & 3.3 & 32 \\
\hline$g \mathrm{ITA}$ & 3.2 & 10.9 & 7.9 & 61.8 & 5.6 & 4.4 & 6.3 & 38 \\
\hline$g \mathrm{JPN}$ & 1.1 & 6.3 & 5.1 & 4.2 & 73.7 & 4.0 & 5.5 & 26 \\
\hline$g \mathrm{UK}$ & 2.9 & 7.9 & 3.7 & 7.5 & 3.9 & 70.6 & 3.5 & 29 \\
\hline$g \mathrm{US}$ & 9.5 & 3.8 & 3.1 & 6.3 & 5.8 & 4.2 & 67.3 & 33 \\
\hline Contr. to others & 19 & 42 & 29 & 39 & 30 & 27 & 32 & Total Spillover \\
\hline Contr. incl. own & 97 & 104 & 97 & 101 & 104 & 97 & 99 & Index $=31.2 \%$ \\
\hline
\end{tabular}

Notes: Spillover indices, given by Equations (2)-(6), calculated from variance decompositions based on 12-stepahead forecasts.

Table A.6: Spillover table (1985M11-2013M8) - Only volatility

\begin{tabular}{lcccccccc}
\hline & \multicolumn{7}{c}{ From $(j)$} & \\
\cline { 2 - 7 } To $(i)$ & $\sigma \mathrm{CAN}$ & $\sigma \mathrm{FRA}$ & $\sigma \mathrm{GER}$ & $\sigma \mathrm{ITA}$ & $\sigma \mathrm{JPN}$ & $\sigma \mathrm{UK}$ & $\sigma \mathrm{US}$ & $\begin{array}{c}\text { Contr. } \\
\text { from Others }\end{array}$ \\
\hline$\sigma \mathrm{CAN}$ & 92.4 & 0.1 & 4.0 & 2.0 & 0.7 & 0.6 & 0.2 & 8 \\
$\sigma \mathrm{FRA}$ & 1.5 & 78.5 & 1.8 & 7.4 & 1.4 & 4.1 & 5.4 & 22 \\
$\sigma \mathrm{GER}$ & 3.7 & 7.4 & 66.2 & 1.8 & 5.2 & 5.4 & 10.3 & 34 \\
$\sigma \mathrm{ITA}$ & 4.8 & 2.7 & 0.0 & 76.1 & 7.3 & 0.9 & 8.2 & 24 \\
$\sigma \mathrm{JPN}$ & 1.5 & 2.5 & 0.4 & 1.4 & 78.5 & 1.8 & 13.8 & 22 \\
$\sigma \mathrm{UK}$ & 2.1 & 1.1 & 3.9 & 8.1 & 0.2 & 82.8 & 1.9 & 17 \\
$\sigma \mathrm{US}$ & 1.3 & 4.1 & 4.5 & 2.9 & 0.9 & 1.0 & 85.3 & 15 \\
\hline Contr. to others & 15 & 18 & 15 & 23 & 16 & 14 & 40 & Total Spillover \\
Contr. incl. own & 107 & 96 & 81 & 100 & 94 & 97 & 125 & Index=20.0\% \\
\hline
\end{tabular}

Notes: Spillover indices, given by Equations (2)-(6), calculated from variance decompositions based on 12-stepahead forecasts. 
Table A.7: Cumulative impulse responses and multiplier effects (1985M11-2013M8) - Only growth

\begin{tabular}{|c|c|c|c|}
\hline & & $\begin{array}{c}\text { Cumulative response }^{1)} \\
\text { From }(j)\end{array}$ & $\begin{array}{l}\text { Implied multiplier effect }{ }^{2)} \\
\text { From }(j)\end{array}$ \\
\hline & $T o(i)$ & $g$ & $g$ \\
\hline 6-months & $g$ & 1.1299 & 1.0382 \\
\hline 12-months & $g$ & 1.1953 & 1.0834 \\
\hline 24-months & $g$ & 1.2049 & 1.0995 \\
\hline 36-months & $g$ & 1.2051 & 1.1378 \\
\hline 48-months & $g$ & 1.2051 & 1.1378 \\
\hline 60-months & $g$ & 1.2051 & 1.1378 \\
\hline
\end{tabular}

Notes: ${ }^{1)}$ Cumulative generalized impulse response to one standard deviation shock, multiplied by 100 (in \%).

2) Multiplier effect, calculated as ratio of cumulative response to incipient shock to the respective country.

All entries are averages over country-specific shocks to the respective variable.

Table A.8: Cumulative impulse responses and multiplier effects (1985M11-2013M8) - Only volatility

\begin{tabular}{|c|c|c|c|}
\hline & & $\begin{array}{c}\text { Cumulative response }^{1)} \\
\text { From }(j)\end{array}$ & $\begin{array}{c}\text { Implied multiplier effect }{ }^{2)} \\
\text { From }(j)\end{array}$ \\
\hline & To (i) & $\sigma$ & $\sigma$ \\
\hline 6-months & $\sigma$ & 1.8631 & 2.5768 \\
\hline 12-months & $\sigma$ & 2.9153 & 4.6807 \\
\hline 24-months & $\sigma$ & 3.7009 & 6.5144 \\
\hline 36-months & $\sigma$ & 3.8797 & 7.0047 \\
\hline 48-months & $\sigma$ & 3.9527 & 7.0431 \\
\hline 60-months & $\sigma$ & 4.0076 & 7.1074 \\
\hline
\end{tabular}

Notes: ${ }^{1)}$ Cumulative generalized impulse response to one standard deviation shock, multiplied by 100 (in \%).

2) Multiplier effect, calculated as ratio of cumulative response to incipient shock to the respective country.

All entries are averages over country-specific shocks to the respective variable. 